\title{
A prediction model coupling occupant lighting and shading behaviors in private offices
}

\author{
Yan Ding ${ }^{1, *}$, Xiaoru $\mathrm{Ma}^{1}$, Shen $\mathrm{Wei}^{2}$, Wanyue Chen ${ }^{1}$
}

1. School of Environmental Science and Engineering, Tianjin Key Laboratory of Indoor Air Environmental Quality Control, Tianjin University, Tianjin, 300072, China

2. The Bartlett School of Construction and Project Management, University College London (UCL), 1-19 Torrington Place, London WC1E 7HB, United Kingdom

*Corresponding author. Tel.: +86 13821601196. Fax: +86 02287891898. E-mail address: jensxing@126.com

\begin{abstract}
Lighting control in office buildings is driven by occupant's demand for indoor light environment. The control behavior not only has a direct impact on occupants' visual comfort, but also relates with the building lighting energy consumption. However, due to the effect of glare, lighting control is often associated with shading adjustment. In this regard, this paper proposed a prediction model which can accurately describe the lighting and shading coupling control behavior by fully considering the difference and diversity of occupants. The light environment preferences and the usage habits of lighting and shading system of occupants was firstly investigated and classified by means of questionnaire. Markov model and log-logistic survival model were introduced to quantitatively describe the probability distribution of various shading and lighting control behaviors. On this basis, combined with the indoor workplane illumination prediction model, the behavior of occupant's lighting and shading coupling control can be predicted. By comparing the four models considering or not considering the diversity and coupling effect, it is found that the proposed coupling prediction models show better performance, the maxium error rate is only $13.04 \%$ for the lighting energy consumption prediction.
\end{abstract}

Key words: Occupant behavior; Classification of occupants; Coupling control behavior prediction model; Survival model; Markov model;

\section{Research Highlights:}

- A prediction model of lighting and shading coupling control behavior is proposed.

- The preferences and control habits of occupants were investigated and classified.

- The indoor workplane illumination was predicted by a machine learning model.

- The preference diversity and correlation between the two behavior greatly affect the prediction accuracy.

\section{Introduction}

Globally, buildings account for nearly $40 \%$ of society's total energy consumption [1], and lighting contributes to about 30\% 50\% of this [2]. Therefore, a good understanding on how lighting systems are being used by building occupants are extremely important for saving lighting energy consumption, which is affected mainly by two main behaviors of occupants, namely, lighting behavior [3] and blind behavior [4].

To estimate the impact of lighting usage on buildings' energy consumption, building performance simulation has been widely used as an economical and effective method to support both system selection and system operation [5]. In 
popular simulation packages, such as IES VE [6] and Designbuilder [7], two approaches are being used for defining lighting system operation, which are: 1) setting fixed schedules to control lighting states, i.e. on or off, and 2) setting photosensitive points, so lighting fraction and output brightness can be controlled according to the level of daylight indoors (Step control or Continuous Dimming control) [8]. For the multi-occupant offices in office buildings, occupant behaviors are influenced by the social relationship and complex interactions between them. Individual differences are hardly presented when adjusting lighting or shading devices. In the private offices, on the contrary, occupants' diversity of lighting and shading usage can be considered.

In real private office, however, occupants' lighting usage is really stochastic due to their different preferences and control habits, and this has led to a key issue in current construction design, namely, performance gap, referring to the significant performance difference between design and actual operation $[9,10]$. To bridge this gap, Gilani et al. [11] have suggested to use dynamic occupant behavior models derived from real buildings to guide simulation definition.

1) Lighting behavior modeling

Now adays, researchers have done many studies on dynamic occupant behavior modeling for lighting control. To quantify the impact of occupants' lighting behavior on building energy demand, many models have been developed to predict occupants' lighting usage in real buildings, including statistical mode, deterministic models and stochastic models [12]. Statistical models use cumulative frequency to generate probability distributions of lighting control. This kind of models, however, The lighting state transition is modeled by the independent random numbers at each time step, rather than by defining the probability of lighting switch on/off event taking place, which is not suitable for individual description or hour-by-hour simulation. The deterministic model proposed by Mahdavi et al. [13] represent probability of using lighting systems in binary form, i.e. either 0 or 1 , which is a step function. Although occupant behavior in buildings is influenced by physical conditions, it is stochastic rather than deterministic. To describe occupant lighting behavior more accurately, Hunt et al. [14] fitted probability curves of lighting control with illuminance level at the work plane. Using this model, Reinhart et al. [15] constructed probability models of lighting control for both arrival time and intermediate time in offices. Taking departure time as an independent variable, the probability relationship between departure and turning off lights has been defined by survival analysis. Gilani et al. [11] have used logistic regression analysis to model occupant's lighting control behavior, and Wang et al. [16] have developed a Weibull's three-parameter probability model to describe the probability of when occupants turning on lights. Yan et al. [12] compared and evaluated all above three stochastic methods and pointed out that Hunt's model was slightly worse than the Weibull model in terms of predicting total energy consumption, hourly energy consumption and operation frequency. However, the Weibull three-parameter model[16] has disadvantages as well. The model needs to set a trigger illumination value and under this value the probability of occupants turning on light is 0. Apparently this compulsory setting is not in line with actual situations. In fact, it is still possible for occupants to turn on lights above this illumination level, so the behavior model developed by this method cannot be considered as completely stochastic.

2) Shading behavior modeling

Dynamic models of shading use are in need to improve the prediction accuracy of energy and daylighting simulation[17-18]. Studies on shading behavior is more complicated, including not only movement of shading devices, i.e. pulling up or down, but also the magnitude of adjustment. Yao et al. $[19,20]$ used outdoor solar radiation as a driving factor and adopted Markov models to model shading adjustment. Some other researchers have combined logistic regression models with other models to describe this behavior. For example, Robinson et al. [21] combined logistic regression models, Markov models and survival models. Seyed Amir Sadeghi et al. [22] combined layered bayesian models with logistic regression models to describe the shading behavior, with greatly improved prediction accuracy. At present, there are just a few studies on shading behavior, and researchers mainly used logistic regression 
to establish shading behavior models. Exisitng shading behavior models, however, only considered fully open or fully closed states, which is not in line with real shading operation in buildings. Weibull survival model is relatively complex, it is necessary to model the shading probability distribution of different illuminances. Although the Markov model proposed by Yao et al. [19] could reflect dynamic transfer of shading positions, outdoor lighting environmental parameters should be added as the main driving factors, without considering impact from different orientations.

In view of existing dynamic models of lighting and shading behaviors, very few of them has considered the coupling between the two. Even though the lightswitching-2002 algorithm proposed by Reinhart et al.[23] has tried to couple lighting and shading behaivors, the diversity in shading behavior has not been considered. Instead, $50 \mathrm{~W} / \mathrm{m}^{2}$ solar radiation was used as a threshold to judge the shading position, with shading positions set as either 0 or 1 . In addition, Seyed Amir Sadeghi et al.[22] used the layered Bayesian method to explore both lighting and shading behaviors, and considered occuapnts' needs in outdoor viewing, privacy preferences and gender in the modeling process of shading. The study showed that besides environmental variables, occupant attributes were significant predictors of occupant interactions, and contributed to improving predictive performance when incorporated as features in shading behaivor models. The modeling of lighting in this study, however, did not consider different preferences between individidual occupants, which as been highly emphasized by Wei et al. [24] for modeling occpant behavior. Gunay et al. [25] have used simulation to compare satisfaction degree between manual operation, automatic control algorithms and adaptive control algorithms. It has been proposed that occupants were more eager to obtain a customized indoor environment, and the preference difference between occupants was definitely deserving consideration. In addition, both Robinson et al. [21] and Gunay et al. [26] also mentioned the importance of the sequence of occupant behaviors in their studies.

The difference and diversity among occupants is the key parts in describing and characterizing occupant behaviors. D'oca and Hong [27] applied cluster analysis method to classify the opening and closing windows behaviors for office rooms according to the influencing factors, such as duration of window state, number of window position changes and the most frequent degree of window opening. Yu et al. [28] used data mining technology and cluster analysis to divide occupants into several categories according to environmental factors and occupant behaviors. The methods described above are limited to cases where measurements are being investigated, and because these patterns are derived from specific data sets and depend heavily on the measurem ents, they cannot be extrapolated to other occupants or buildings. In order to enhance the universality of the methods, Feng et al. [29] investigated and made statistics on the use patterns of air conditioners to categorize occupant behaviors based on questionnaires, and received several typical air conditioning behavior patterns based on the simulated energy consumption of air conditioners.

According to the above review work, it could be found that existing behavioral models often work separately. Even though some studies have considered coupling between lighting and shading behaviors, the diversity between occupants was not fully addressed. Until now, there is still no effective method that can combine both coupling and diversity when modeling and predicting occupant behavior in buildings. In real buildings, however, there is no doubt that shading behavior will affect the amount of daylight indoors, and hence affecting occupants' lighting behavior. Additionally, existing models model building occupants as a whole or define models for certain groups of occupants, such as occupants located on different façades or floors, in a building. Individual diversity between occupants has not yet well reflected in existing methods, especially when considering more than one behavioral types. To deal with these issues, this study has developed a preference-based classification approach for building occupants using questionnaires, and corresponding behavioral models were developed for each type of occupants considering both their shading and lighting behaviors. Field behavioral data with relevant influential data were collected from a real 2-storey office building located in south China. The popular stochastic modeling approach combining Log-logistic and Markov chain was adopted in this study to develop behavioral models for both shading and lighting controls. To justify the 
advantages of the new method proposed in this study, its performance on predicting occupant behavior has been compared with the more conventional methods and results were well discussed in the paper.

In the remaining part of this paper, Section 2 described the main research methods adopted in this study, including data collection, occupant classification and behavior modelling. Section 3 explained the behavioral models developed using the approach proposed in this study and compared its prediction performance against more conventional methods, with appropriate discussions. Main findings from this study and possible future work were provided in the last section of the paper.

\section{Methodology}

\subsection{Research framework}

In this study, occupants' lighting and shading preferences were determined by a coupling control behavior prediction model. Combining classifying occupants at three different steps, the model aimed at reflecting the judgment made by occupants to meet their demands on indoor light environment The indoor workplane illumination was predicted by a machine learning prediction model and acted as an indicator to predict the coupling control behavior of shading and lighting.

The research framew ork proposed in this study was shown in Fig.1.

Measurement \& Investigation
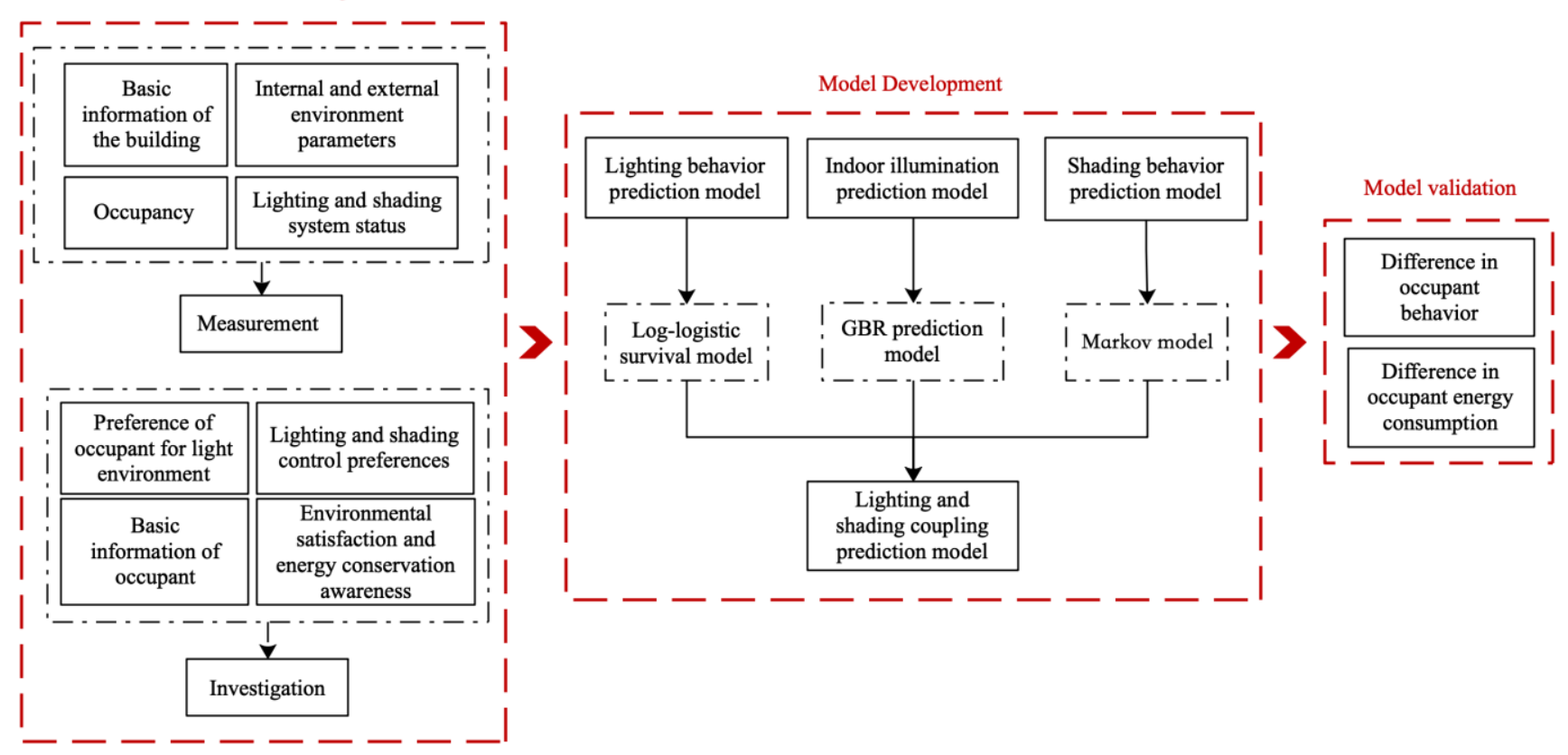

Fig. 1 Proposed research framework

According to the framework of this study, it can be divided into three parts. The first part is the measurement and investigation. The measured data in the case building and the questionnaires on control habits of the occupant were collected. The second part is the model development, including the development of lighting model, shading model and indoor illumination prediction model. And the coupling control prediction model is finally established based on the above three models. The third part is the model validation. Through the comparison of the actual behavior frequence and measured lighting energy consumption, the prediction performance of the coupling model was validated. 


\subsection{Case study building}

A 2-storey office building located in Wuhan, China has been selected as the case office building for this study, as shown in Fig. 2. The building has a platform monitoring energy consumption, including hourly data on lighting, air conditioning and equipment for each office. As the main objective of this study is to explore the coupling modeling of lighting and shading behaviors, 12 private offices facing south were selected in this study, due to their huge impact on solar and daylight. Table 1 has listed some basic information about all monitored offices in this study.

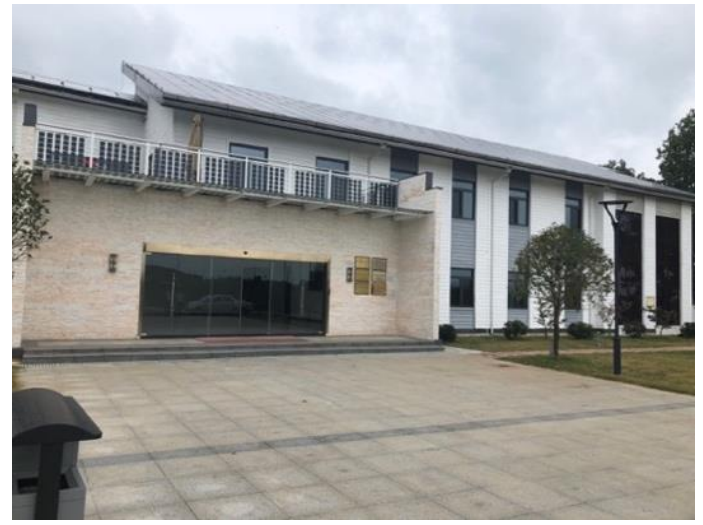

(a) External view

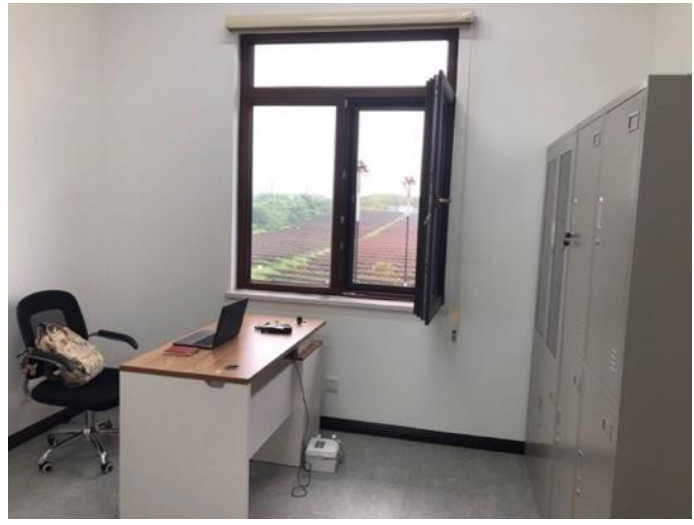

(b) Internal view

Fig. 2 The case study building

Table 1 Basic information about monitored offices

\begin{tabular}{cccc}
\hline Category & Information & Category & Information \\
\hline Office type & private office & Shade type & Manual roller shade \\
Office orientation & South & Shading visible transmittance & $2.1 \%$ \\
Office area & $10.25 \mathrm{~m}^{2}$ & Light type & LED \\
Window type & LOW-E & The power of lighting & $30 \mathrm{~W} \times 3$ \\
Window size & $1.65 \mathrm{~m} \times 0.8 \mathrm{~m}$ & Lighting power density & $8.78 \mathrm{~W} / \mathrm{m}^{2}$ \\
Window visible & & Illumination provided by the \\
transmittance & $80 \%$ & Lighting system & $462 \mathrm{lux}$ \\
\hline
\end{tabular}

\subsection{Data collection}

Field measurements and questionnaire surveys were both used in this study to get useful information for the analysis, including light environmental parameters, states of both shade and lighting, and behavioral preferences of occupants. 


\subsubsection{Field measurement}

The longitudinal measurement was lasting for a total of 90 days, from $2^{\text {nd }}$ July to $30^{\text {th }}$ September, 2018, including 65 working days. The measurement was done by a local outdoor weather station and some indoor sensors in the 12 south-facing offices. The measurement time was between 9am and 5pm. During working days, occupant control behaviors on both lighting and shading were measured and recorded, with corresponding indoor and outdoor light environmental parameters as well. The measurement was divided into two phases:

- Phase 1: It is mainly from the first month including 23 working days and 8 non-working days. Measurement was conducted on weekdays to explore the effect of different initial shading positions based on the adjustment behavior. In this phase, the shading positions were reset manually at the end of each day. The initial shading position from Monday to Friday were 0\%, 25\%, 50\%, 75\%, and 100\%, respectively. The data in this phase is mainly applied to the analysis of indoor illumination change and shading position change under different initial shading positions respectively in section 3.1 and section 3.3, and also applied to the development of the models of lighting, shading and indoor illumination prediction.

- $\quad$ Phase 2: It is mainly from the second month including 22 working days and 8 non-working days.In order to eliminate the influence of initial shading position on occupants' behavior, the initial shading position of all monitored offices were set to $0 \%$ before the start of the second phase. When the seconde phase measurement started, the initial shade position in one day was the last shading position of the previous day.And once the measurem ent begin, the adjustment of shading will be entirely up to the occupants in the room, which aims at observing the long-term adjustment behavior of different types of occupants. The data in this phase is mainly applied to the model validation in section 3.6.

In all non-working days, the shading were adjusted to different positions ( 5 positions in total) at each moment of measurement to observe hourly variation of indoor illumination at different shading fractions. No measurement of occupant behavior was performed in non-working days, as all monitored rooms were not used.

During the whole monitoring period, the following parameters were measured by proper sensors:

- Outdoor solar radiation: a HOBO weather station was installed locally on the roof of the building. Outdoor solar radiation was colleted by a light sensor (S-Lib-M003), with measurement range of $0-1280 \mathrm{~W} / \mathrm{m}^{2}$, and accuracy of $\pm 5 \%$ of reading.

- Outdoor illumination: a illuminometer (T-10A) was used for measuring outdoor illumination, with measurement range of 0-299,900lux, and accuracy of $3 \%$ of reading.

- Work plane illuminance: a illuminometer (199-lx) was used for measuring illuminance on the work plane of each office and recording illuminance status of work plane at different times during the day. It's measurement range is $0-200,000 l u x$, and accuracy of $4 \%$ of reading. The sensor was placed facing up on a desk in the center of the work area, and participants have been advised to keep their sensors unobstructed.

- Work plane daylight illuminance: Calculated from the difference between measured total illumination of work plane and illumination of work plane only under lighting conditions (real-time measurement of illumination of work plane at night under lighting conditions).

- Lighting status: a Fluorite C3A camera was installed to monitor occupants' lighting behavior. The maximum wide angle of the equipment monitoring is $125^{\circ}$, and the maximum monitoring distance is $10 \mathrm{~m}$.

- Shading position: the adjustment of shading positions by occupants was monitored by the camera as well.

- Occupancy: The camera was also used for monitoring occupancy of rooms.

Fig. 3 depicts the layout of a sample monitored office, including the seating position of participants, window position and the monitoring equipment installation position. 


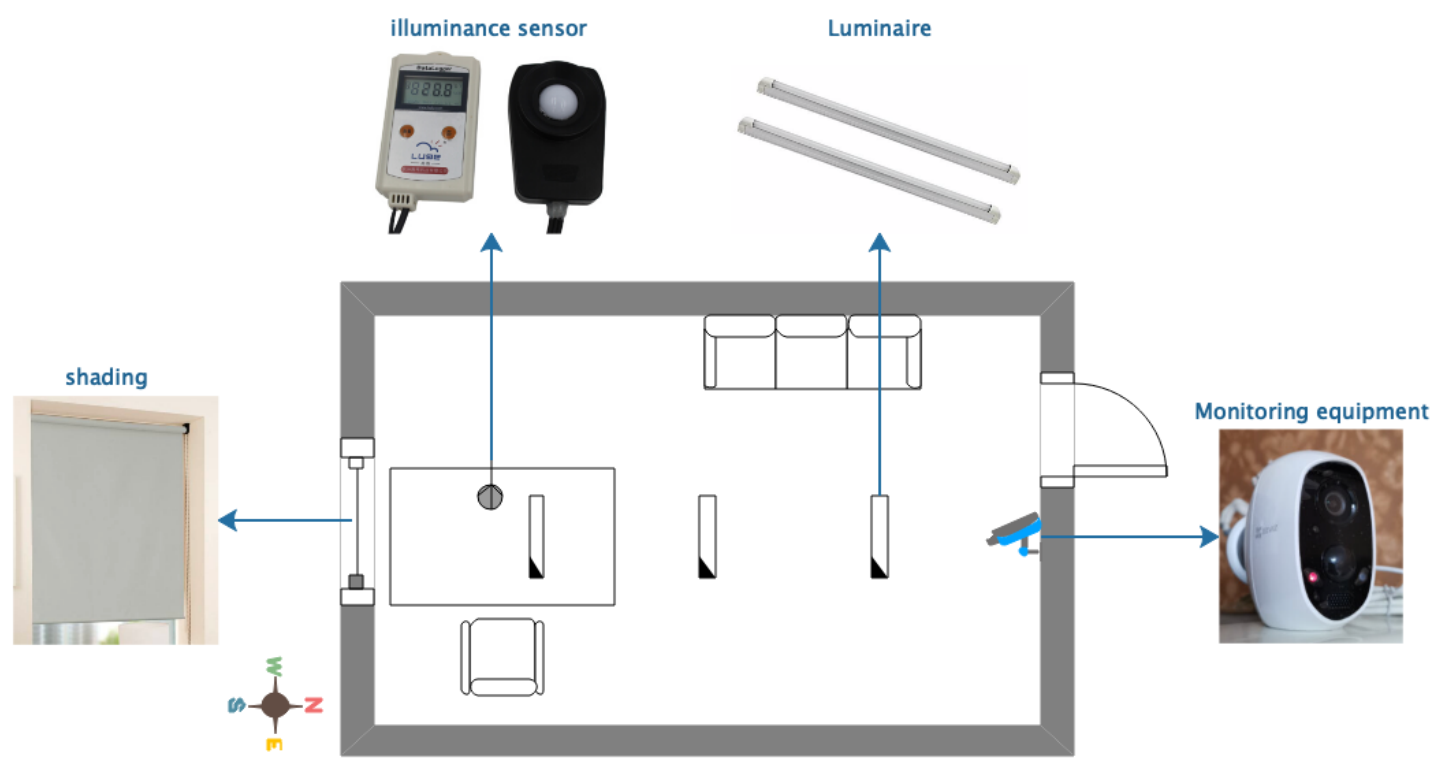

Fig. 3 Layout of a sample monitored office

\subsubsection{Questionnaire survey}

To obtain behavioral preferences of monitored participants, questionnaires were distributed. The contents of the questionnaires mainly included: types of light environment preferences, acceptability of light and dark environment and light sensitivity. The detailed contents of the questionnaires are shown in Tables 4, 5 and 6.

Considering that there were only 12 south-facing private offices monitored in this study, to determine the usage patterns of their 12 occupants, questionnaires were distributed to them before the field measurement. It is worth noting that since the questionnaire was designed only to obtain the coupling control pattern of the occupants in the building, only the 12 occupants in the south-facing offices were investigated and the questionnaires were not distributed to the occupants who did not participate in this study.

\subsection{Model development}

\subsubsection{Lighting and shading model}

To establish occupants' coupling control behavior model, lighting and shading were firstly modeled and described individually and then combined with the classification of coupling type and the black box model for indoor work plane illuminance prediction.

\section{1) Lighting model}

Compared with other methods, the survival model can better reflect the relationship between event occurrence and time, and it can well represent the changes in the probability of turning off the lights as the duration of occupant absence increases. The survival estimates obtained from the parametric survival model are usually more consistent with the theoretical survival curve than from the ordinary survival model. For a survival model, independent variables are not limited to time, so in this study the lighting control probability was used in a Log-logistic model describing occupant controlbehavior on lighting systems. Log-logistic is one of the parametric survival models, which 
assume that the survival time (results) follows a known distribution.

For a Log-logistic model, the survival function is shown in Equation (1):

$$
S(t)=\frac{1}{1+\lambda t^{p}}
$$

The probability distribution is shown in Equation (2):

$$
p=1-S(t)=1-\frac{1}{1+\lambda t^{k}}
$$

where $p$ is the probability of turning off light; $t$ is the duration of absence, min; $\lambda, k$ are two coefficients.

By deformation, Equation (3) can be used as a behavioral model to describe the probability of turning on light,

$$
\mathbf{p}=1-\frac{1}{1+\left(\frac{x-\gamma}{\lambda}\right)^{k}}
$$

where $\mathrm{p}$ is probability of turning on light; $\mathrm{x}$ is indoor illuminance, in $\mathrm{lx} ; \gamma, \lambda, \mathrm{k}$ are coefficients.

\section{2) Shading model}

Shading adjustment reflects the stochastic nature of occupants' behavior. Therefore, the characterization of shading behavior requires stochastic modeling. For other Stochastic model, they produce the probability of an action given a set of environmental conditions as inputs. However, the adjustment of shading is not only related to environmental conditions but also to the current position of shading. Thus, the Markov model was adopted in this study to describe adjustment of shading systems. And the work plane illuminance has been taken as the driving factor. Let Markov chain $\mathrm{X}$ at time Step $\mathrm{k}$ be time series $X\left(t_{1}\right) X\left(t_{2}\right) \ldots, X\left(t_{k}\right)$, shading state $\mathrm{S}=\left\{\mathrm{S}_{1}, \mathrm{~S}_{2}, \ldots, \quad \mathrm{S}_{\mathrm{n}}\right\}$, where $\mathrm{n} \leq \mathrm{k}$.

When using Markov chains, the next shading position only depends on the current state, not the previous ones, with an expression as followings,

$$
\begin{array}{r}
P\left\{\left(X\left(t_{n}\right)=S_{n} \mid X\left(t_{1}\right)=S_{1}, X\left(t_{2}\right)=S_{2}, \ldots, X\left(t_{n-1}\right)=S_{n-1}\right)\right\} \\
=P\left\{\left(X\left(t_{n}\right)=S_{n} \mid X\left(t_{n-1}\right)=S_{n-1}\right)\right\}
\end{array}
$$

where $n-1$ and $n$ indicate the current and the next time step; $S_{n-1}$ and $S_{n}$ represent two states; Prepresents the transition probability.

If all model parameters are constant, the Markov chain becomes denominated time-homogeneous Markov chain (or stationary Markov chain). It means that the model transition matrix is a constant time-invariant matrix and can be expressed by Equation (5), which describes a system that undergoes state transitions with a certain probability.

$$
P=\left[\begin{array}{cccc}
P_{11} & P_{12} & \cdots & P_{1 j} \\
P_{21} & P_{22} & \cdots & P_{2 j} \\
\vdots & \vdots & \cdots & \vdots \\
P_{i 1} & P_{i 2} & \cdots & P_{i j}
\end{array}\right]
$$

where, $p_{11} \ldots \ldots, p_{m m}$ is the transfer probability between different shading states.

$P_{i j}$ could be obtained by Equation (6),

$$
P_{i j}=\frac{N_{i j}}{\sum_{1}^{n} N_{i j}}
$$

where, $\sum_{1}^{n} N_{i j}$ represents the total number of times occupant adjusts the shading position from $i$ to any other position; $N_{i j}$ represents the total number of times occupant adjusts the shading position from $i$ to $j$, and $P_{i j}$ represents the probability of moving to $j$ at the next moment when the shading position at the current moment is $i$. 


\subsubsection{Indoor illumination prediction model}

For an accurate building performance simulation, it is necessary to couple the daylight model with occupant preference judgement. To complete this work, a machine learning model was compiled by Python. To predict the hourly indoor illumination, the outdoor illumination, the outdoor solar radiation, the time of the day, the indoor shading percentage and indoor lighting conditions were selected as five input variables in prediction models. The hourly data of the above five variables from Phase 1 and Phase 2 were taken as the training sets and validation sets respectively.

GBDT is a widely used algorithm, which can be used for classification and regression. It works on a lot of data. The Gradient Boosted Decision Trees(GBDT) is proposed by Friedman [30] on the basis of boost algorithm framew ork, using multiple regression tree methods to construct binary models. The basic principle is to reduce the residual of the model by iterative calculation and build a new model in the gradient direction instead of the old one. The modeling process can iteratively generate a combination of basic classifiers to minimize loss function. Suppose that there are N training samples $\left\{\left(x_{i}, y_{i}\right)\right\}_{i=1}^{N}$, where $x_{i}$ is a sample and $y_{i}$ denotes the label of sample $x_{i}$. Let $F(x)$ be a linear combination of individual decision trees, and $L(y, F(x))$ be a loss function. For any sample $x_{i}, F\left(x_{i}\right)$ is the classification (the ith decision tree) of $x_{i}$, and $L\left(y_{i}, F\left(x_{i}\right)\right)$ is the loss between $F\left(x_{i}\right)$ and $y_{i}$.The goal of GBDT is to learn an optimal model $F(x)$ such that $\sum_{i=1}^{n} L\left(y_{i}, F\left(x_{i}\right)\right)$ is minimized for a specified loss function L(y, $\boldsymbol{F}(\boldsymbol{x}))$.

$$
F *(x)=F_{0}(x)+v \cdot \sum_{t=1}^{m} \rho_{t} \cdot h_{t}(x)
$$

where $m$ is the number of iterations; $v_{0}<v<1$ represents the shrinkage parameter that controls the learning rate of $G B D T ; h_{t}(x)$ denotes the tree trained in the t-th iteration; $\rho_{t}$ is the weight of $h_{t}(x)$. The main procedures of GBDT algorithm is displayed in Table 2

Table 2 Algorithm of Gradient Boosted Decision Trees

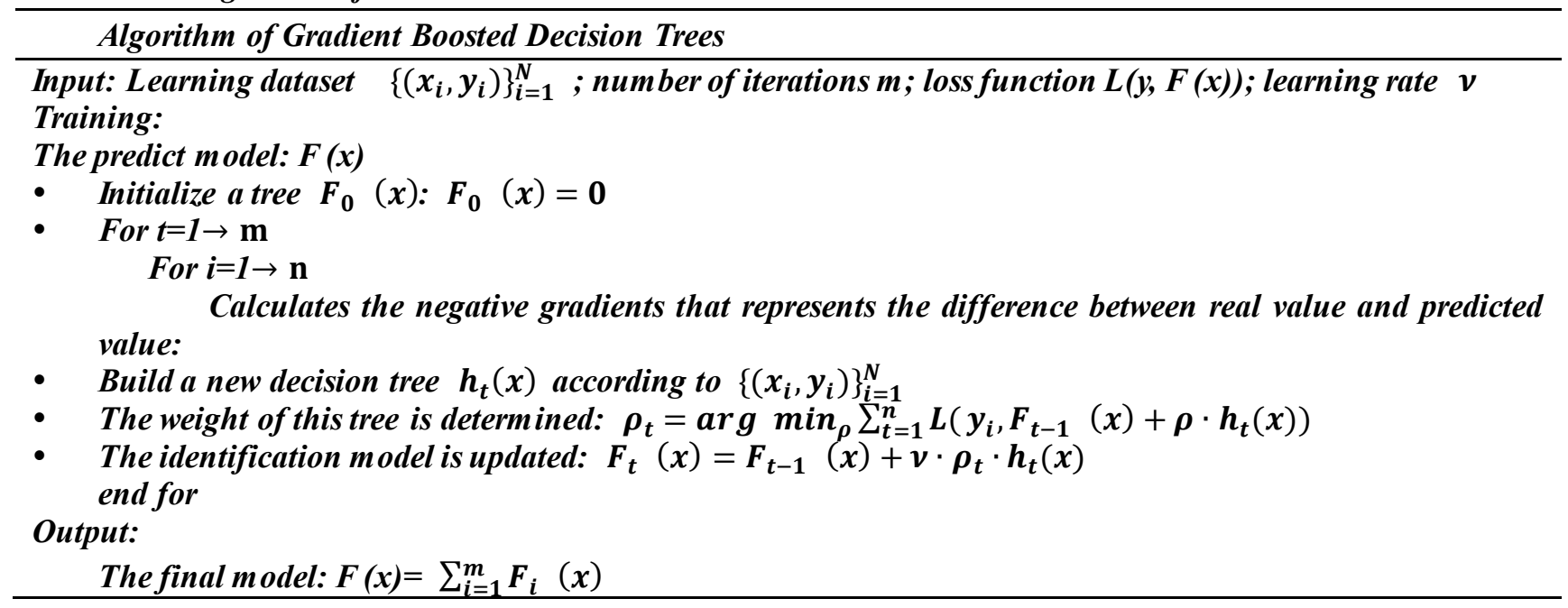

Gradient Boosting Regressor (GBR) for regression and Gradient Boosting Classifier (GBC) for classification are two applications of the GBDT algorithm in Python. In order to determine whether this method is suitable for this study, we evaluated GBR, and the regression indexes obtained are shown in Table 3.

Table 3 Regression indexes of GBR

\begin{tabular}{lllll}
\hline & EV & MAE & MSE & R2 \\
\hline GBR & 0.996086 & 31.768314 & 1987.54813 & 0.996086 \\
\hline
\end{tabular}

As can be seen from Table 3, GBR shows good performance in all kinds of indicators, and its R2 reaches about 0.996. It can be considered that it can well explain the change of indoor workplane with five input variables. Therefore, 
it can be considered that GBR is applicable to this study. And a specific schematic diagram of the modelng work is depicted in Fig.4.

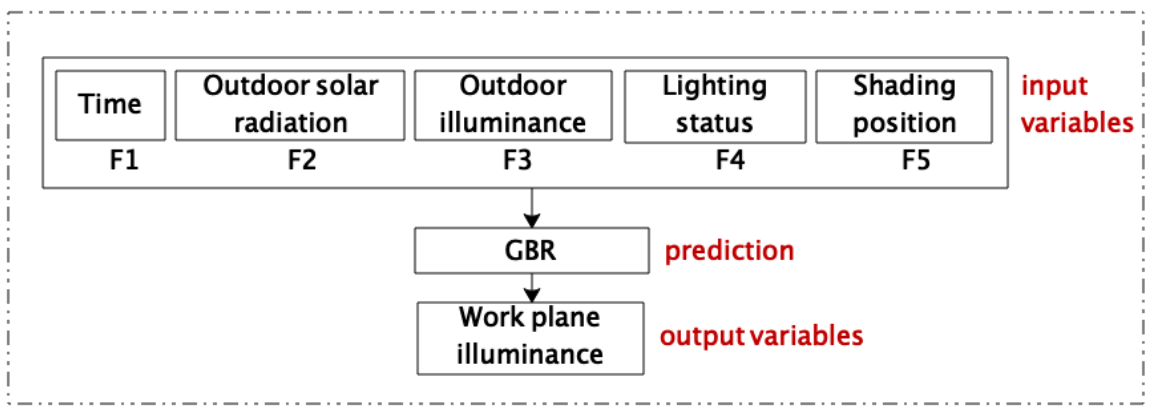

Fig.4 Indoor work plane illuminance prediction model

\subsubsection{Lighting-shading coupling control prediction model}

On the prem ise of developing the lighting model, shading model and indoor illumination prediction model, the preference types and control habits of occupant were classified according to the questionnaires, and the coupling control model was finally completed (as shown in Fig. 6).

The main steps for the classification of occupant are as follows:

\section{1) Step 1: Determining occupants' preference type to light environment:}

To decide occupants' preference types on light environment, the questions, options and corresponding pattern definitions listed in Table 4 were used in this study.

Table 4 Determination on light environment preference types:

\begin{tabular}{c|cc}
\hline \multicolumn{1}{c}{ Question } & Options & Type definition \\
\hline $\begin{array}{c}\text { What do you do when the } \\
\text { indoor light doesn't meet } \\
\text { your requirements? }\end{array}$ & A. Give priority to shading to get enough light & Natural light preference type (N) \\
\hline
\end{tabular}

According to occupants' different priority choic es when the indoor illumination is not sufficient, their preferences were divided into two types: Natural lighting preference type and Lighting preference type. For those who give priority to shading, natural light preference type $(\mathrm{N})$ was given. For those who give priority to lighting, lighting preference type (L) was given.

It is worth noting that no-preference type is excluded in this study. Although it also appears in the questionnaire, such occupant type only accounts for an extremely small proportion and is not conducive to the establishment of models.

2) Step 2: Determining occupants' priority-control preference:

The next judgment was carried out based on the result from the first step. If the occupant was determined as natural light preference type $(\mathrm{N})$, priority was given to the use of shading device to improve the indoor light environment. To obtain occupants' shading usage types, Table 5 has listed the questions and corresponding pattern definitions of relevant options used in this study.

Table 5 Determination on shading control types

\begin{tabular}{c|cc}
\hline \multicolumn{1}{c}{ Question } & Options & Type definition \\
\hline $\begin{array}{c}\text { In what indoor } \\
\text { light conditions } \\
\text { do you adjust }\end{array}$ & $\begin{array}{r}\text { A. Sensitive to light. Pull down the shade when the sunlight is a little harsh, } \\
\text { and pull up the shade when the indoor light is a little dark. }\end{array}$ & $\begin{array}{c}\text { Sensitive type } \\
\text { (S) }\end{array}$ \\
B. Moderate sensitivity to light. Pull down the shading when the sunlight is & Moderate type
\end{tabular}


In Table 5, the shading types of occupant were divided into three categories, namely, sensitive, moderate and insensitive, according to their sensitivity to light. For occupants who are sensitive to light (S), they will draw the shading when the sunlight is slightly harsh and open the shading when the indoor light is slightly dark. For those with moderate sensitivity to light (M), they will pull up the shading when the sunlight is harsh and open the shading when the office is dark. For those who are insensitive to light (I), they will only pull down the shading when the sunlight is very harsh, and only pull up the shading when the indoor light is very dark.

For lighting preference type (L), priority was given lighting to improve indoor light environment. Table 6 has listed the questions and corresponding pattern definitions of relevant options used to decide occupants' lighting usage types in this study.

Table 6 Determination of lighting usage types

\begin{tabular}{|c|c|c|}
\hline Q & Options & Type d \\
\hline $\begin{array}{c}\text { When will you } \\
\text { turn on the } \\
\text { light? }\end{array}$ & $\begin{array}{l}\text { A. Only can accept the brighter working environment, and turn on } \\
\text { the light when the office is slightly darker. } \\
\text { B. Can accept moderate working environment and turn on the light } \\
\text { when it is dark. } \\
\text { C. Can accept dark working environment, and only turn on the light } \\
\text { when it is really dark. }\end{array}$ & $\begin{array}{l}\text { Bright acceptable type } \\
\text { (B) } \\
\text { Medium acceptable type } \\
\text { (M) } \\
\text { Dark acceptable type } \\
\text { (D) }\end{array}$ \\
\hline
\end{tabular}

In Table 6, the lighting use types were divided into three categories, namely, bright acceptable, medium acceptable and dark acceptable. For those who can only accept bright working environment and turn on lighting when the office is slightly dark, they are classified into the bright environment acceptable type (B). For those who can accept moderate environment and turn on lighting when it is dark, they are classified into medium environment acceptable type (M). For those who can accept dark working environment and turn on lighting when it is very dark, they are classified into dark environment acceptable type (D).

\section{3) Step 3: Determining occupants' secondary control type:}

Based on the light environment preference type determined in Step 1, occuapnts' usage type of priority control was determined, and then in Step 2 the judgment of the other equipment system control type (shading or lighting) was done. For natural daylighting preference type $(\mathrm{N})$, shading was given priority in controling indoor light environment, so the lighting use type was finally determined at Step 3. For the lighting preference type (L), the priority was given to lighting control, and the determination of shading use type was also completed at Step 3.

Based on the above Three-Step judgment, the determination of occupant types in coupling control in offices is completed. Theoretically, there are 18 occupants types coupling shading and lighting controls, as shown in Fig.5. 


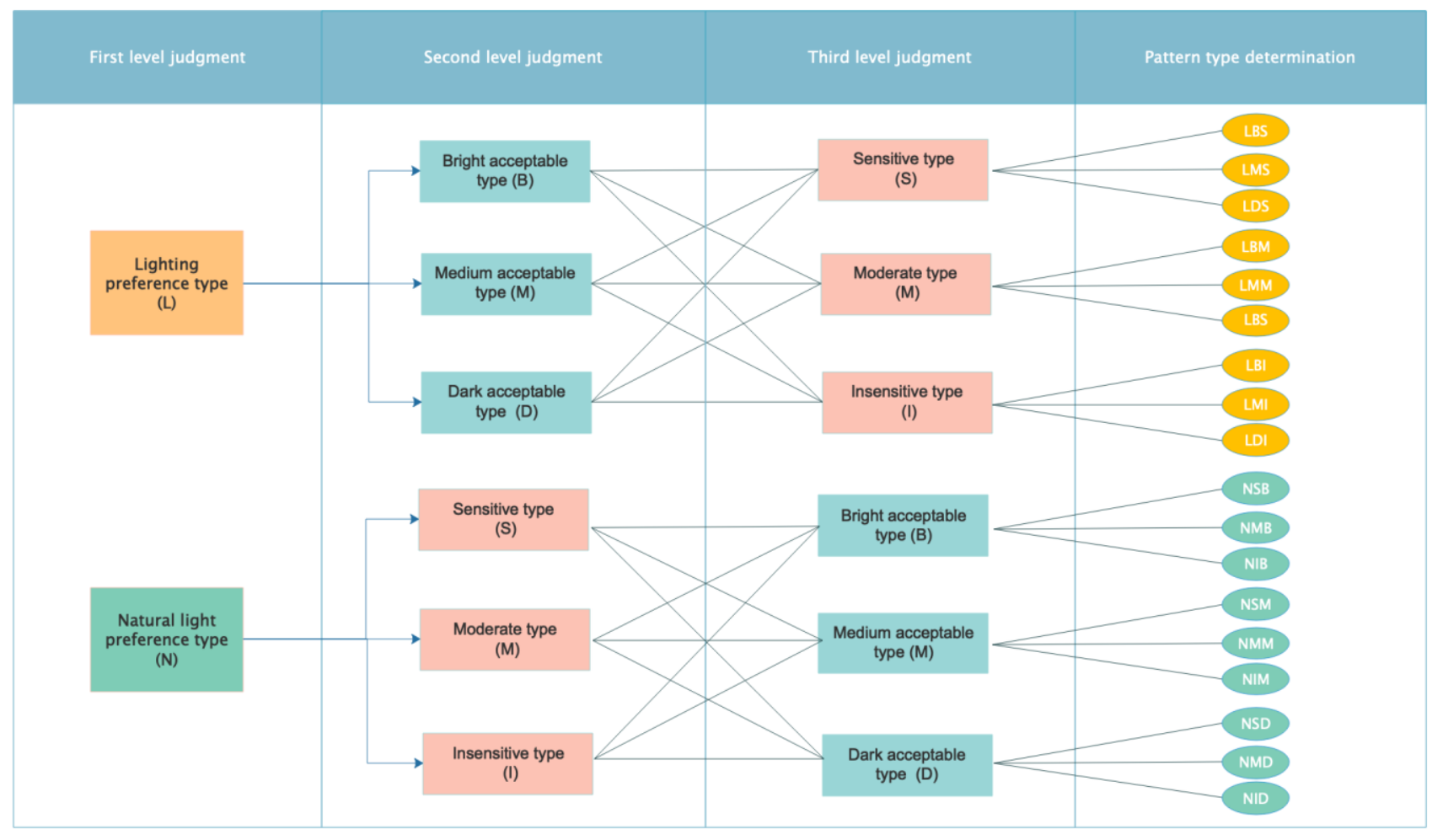

Fig.5 Determination of occupants' coupling control type

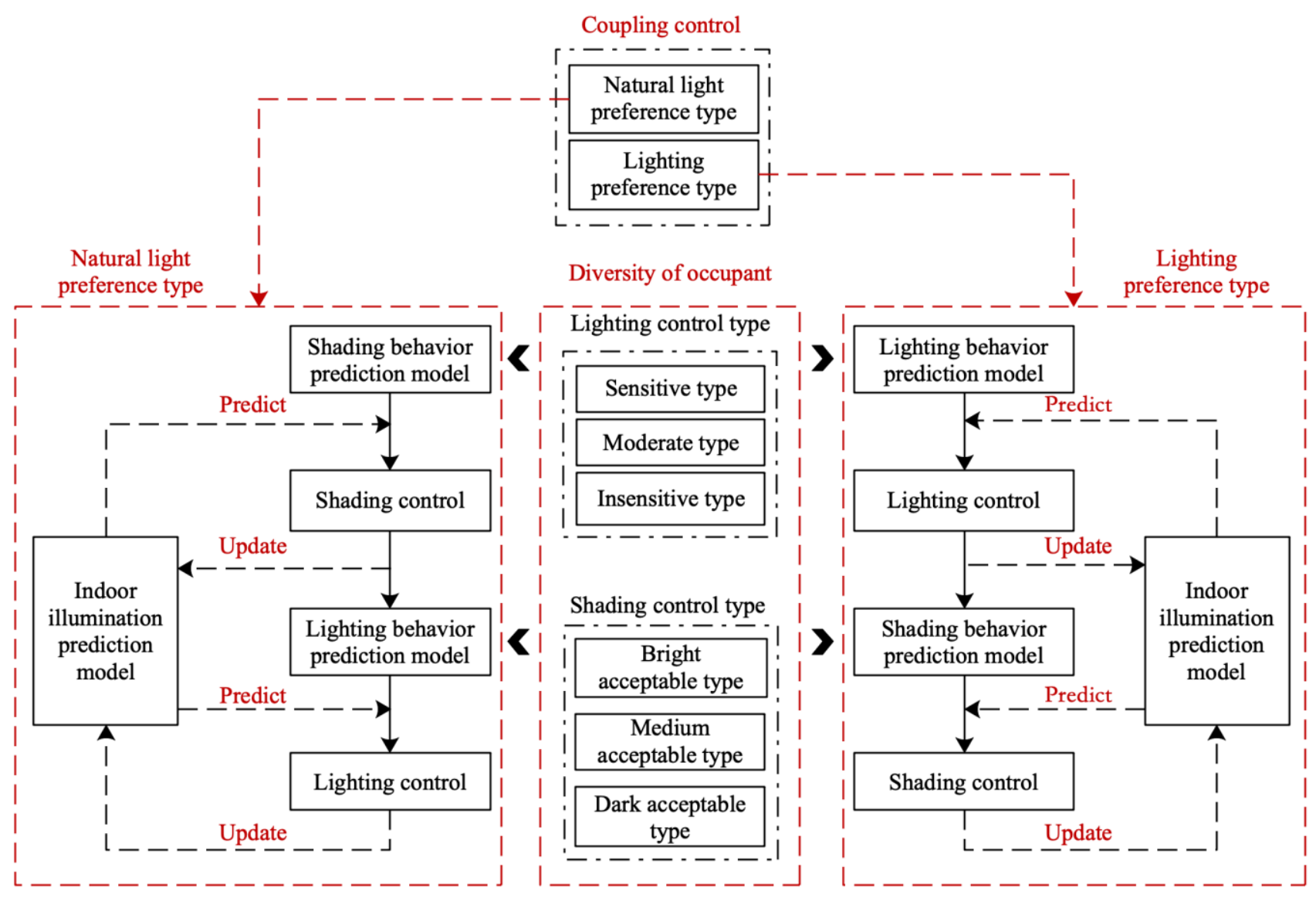

Fig.6 Lighting-shading coupling control prediction 


\subsubsection{Metrics to describe the shading change}

To describe change in the shading fraction, two main metrics have been used by Inoue [31]. One was Mean Shading Occlusion (MSO), defined as the average occlusion fraction of all shades investigated, defined by Equation (8),

$$
M S O_{t}=(1 / n) \sum_{i=1}^{n}\left(P_{i}\right)_{t}
$$

where, $\mathrm{n}$ is the total number of windows; $\mathrm{P}$ is the mean occlusion fraction of the shade at time $\mathrm{t}$.

Another metrix was Shade Movement Rate (SMR), defined as the fraction of shades moved between two discrete time steps, as defined by Equation (9),

$$
\operatorname{SMR}_{\mathrm{t}}=(1 / \mathrm{n}) \sum_{\mathrm{i}=1}^{\mathrm{n}}\left(\mathrm{N}_{\mathrm{i}}\right)_{\mathrm{t}}
$$

where, $\mathrm{n}$ is the total number of windows; $\mathrm{N}$ is the number of fractions of shades moved between two time steps.

\section{Results and Discussions}

\subsection{Variation in indoor illumination}

In order to develop a predictive model for shading position, it is of important to study the variation of the key environmental variables. During the monitoring period, both shading adjustment to one of five different positions and indoor illumination intensity at working plane were recorded with 1-hour interval. Fig.7 plots indoor illumination changes during 9:00-17:00 in 27 non-working days with different shading fractions, including an average line of illumination at different moments.

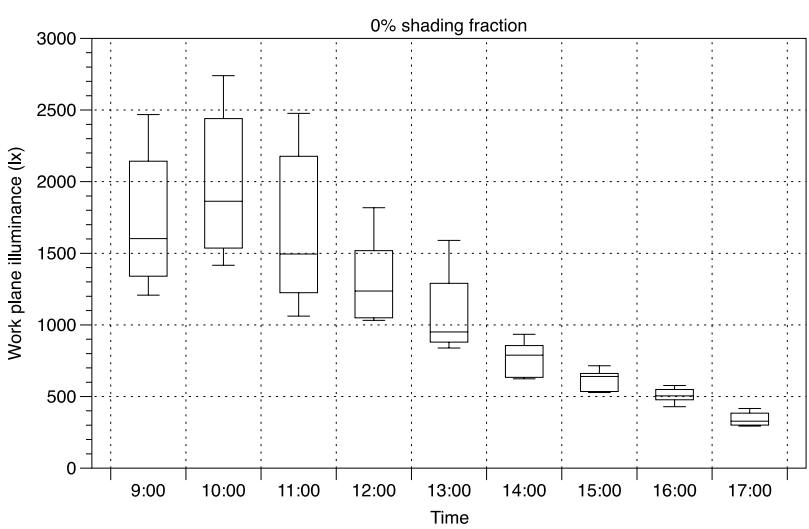

(a)

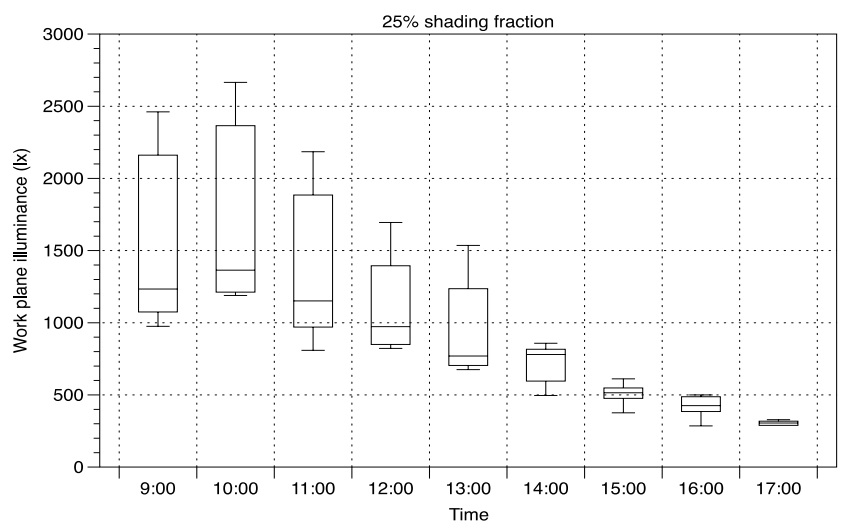

(b) 


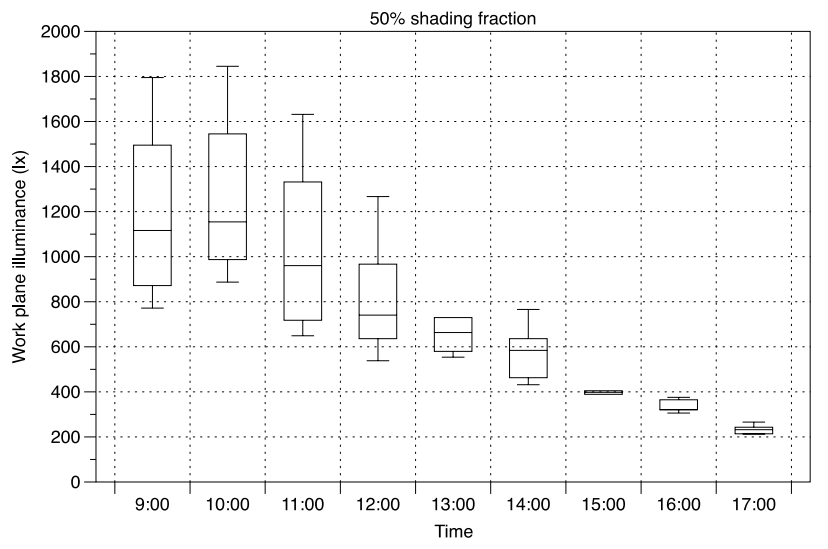

(c)

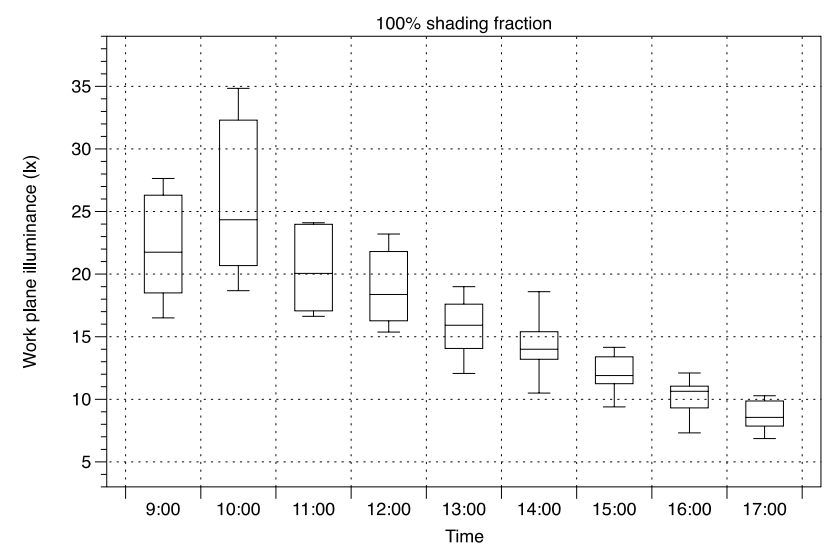

(e)

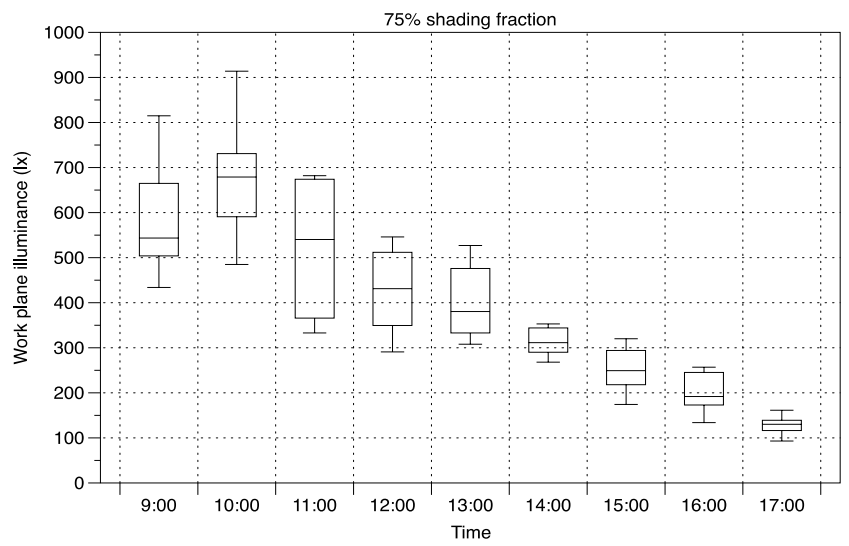

(d)

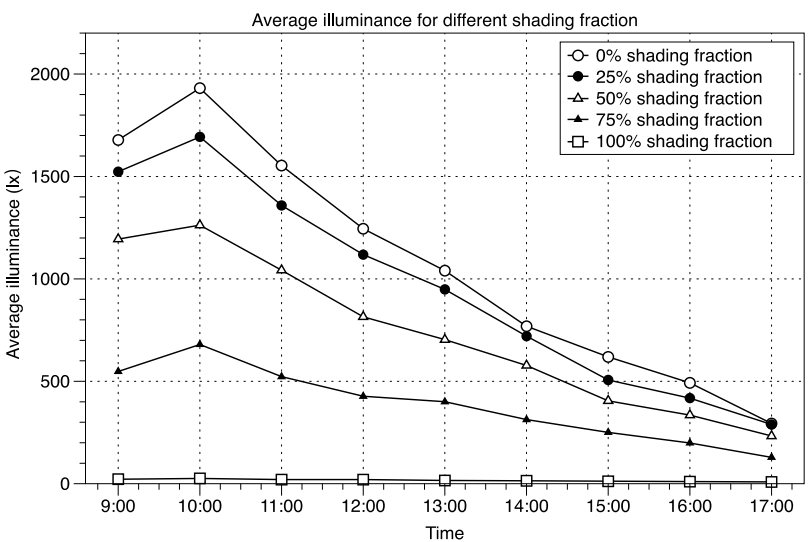

(f)

Fig.7 Illuminance for different shading fractions

From Fig.7 (a) - (e), it could be observed that although the shading fraction was different, the illuminance variation on the work plane under all five shading fractions was similar, showing a trend of rising at the beginning and then falling. The highest illuminance level occurred around 10am but not at the noon or in the afternoon. This was mainly due to existing shade overhanging eaves outside the building, so that the direct light at noon and afternoon is blocked when the solar angle became larger. As depicted in Fig.7 (f), for different shading fractions, the indoor illumination at working plane showed a trend of gradual declining with the increase of shading fraction. The larger the shading fraction was, the more obvious difference of illumination was between the current and the previous shading fractions.

\subsection{Determination of occupant control type}

To determine the 12 occupants' preference types and their control patterns, both the number and proportion of each occupants' preference type and coupling control pattern were obtained from the questionnaire, with some basic statistics shown in Fig. 8. 

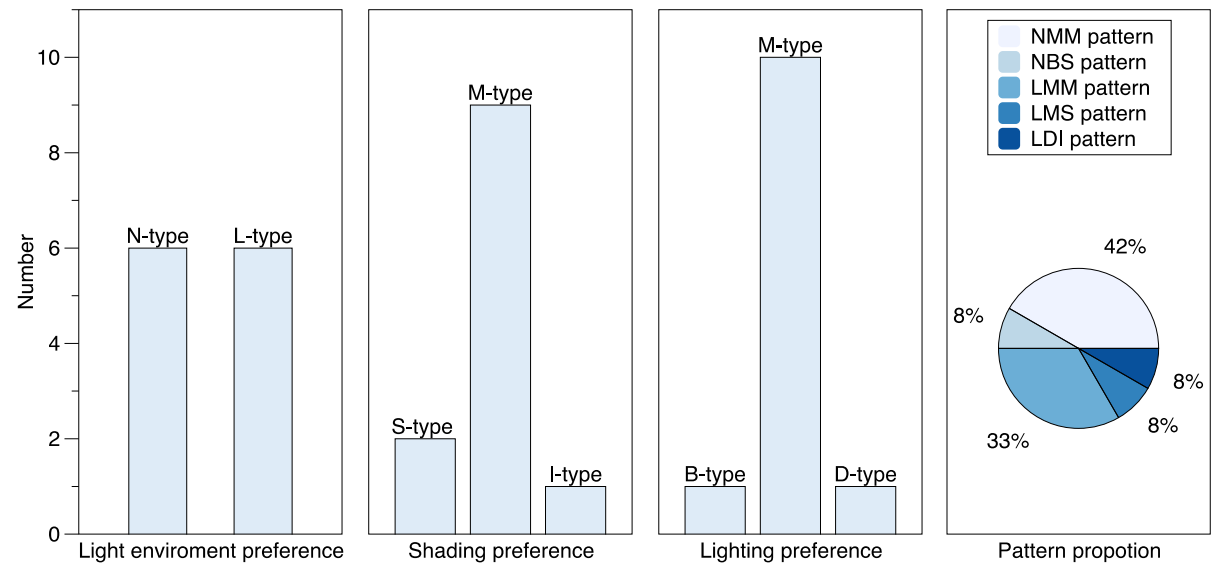

Fig. 8 The number and proportion of occupant in each preference type and control pattern

As can be seen in Fig.8, when indoor illumination was not sufficient, lighting and shading had the same priority. The preference of natural light and lighting systems occupied the same proportion. It can be seen that both shading and lighting controls were dominated by moderate types of occupants. Only five patterns appeared in this investigation, namely, 1) natural light preference - moderate lighting type - moderate shading type (NMM);2) natural light preference - bright environment type - light sensitive type (NBS); 3) lighting preference - moderate lighting type moderate shading type (LMM); 4) lighting preference-moderate lighting type - light sensitive type (LMS), and 5) lighting preferences - dark environment type - light insensitive type (LDI). Among these five patterns, LMM and NMM were the two main patterns with largest proportions.

\subsection{Lighting control behavior analysis and model development}

According to the classification of different preference types from the questionnaire, the offices occupied by occupants with three different lighting control types (sensitive, moderate and insensitive type )were monitored. The work plane illuminance was selected as the driving factor, and the turning on probability of various types of occupants under different illumination was calculated (Fig.9), and the lighting control behavior of each type was modeled. In fact, once lighting was on, occupants tend to keep their state unchanged until they leave the office [32]. Sometimes, when indoor daylight level is high, occupants even do not notice that the lights are on, and so they do not turn lights off [33]. Therefore, this study only focused on occupants' lighting behavior when they left their offices, ignoring the situation of turning off lighting when they are in the office. In addition, types of occupants were not distinguished on turning off probability when they were leaving their offices. The models and parameters of different types of occupants are shown in Table 7.

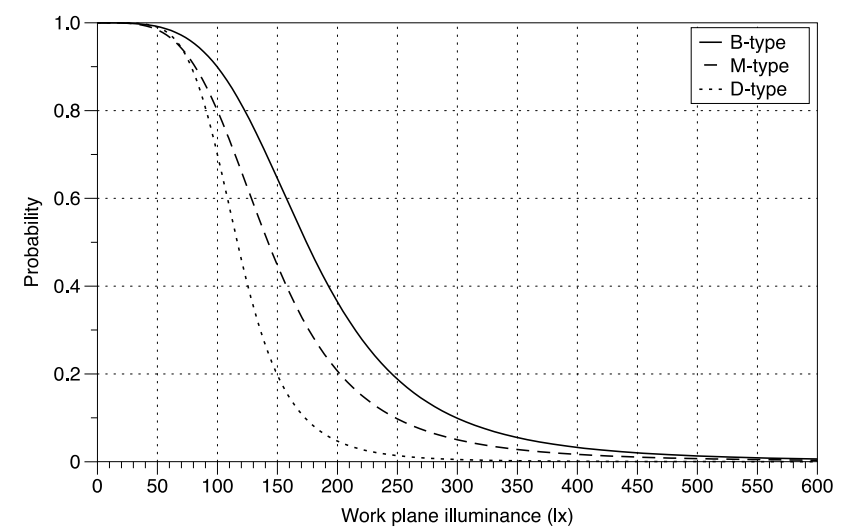

(a) Probability curve of lights on for different types of occupant

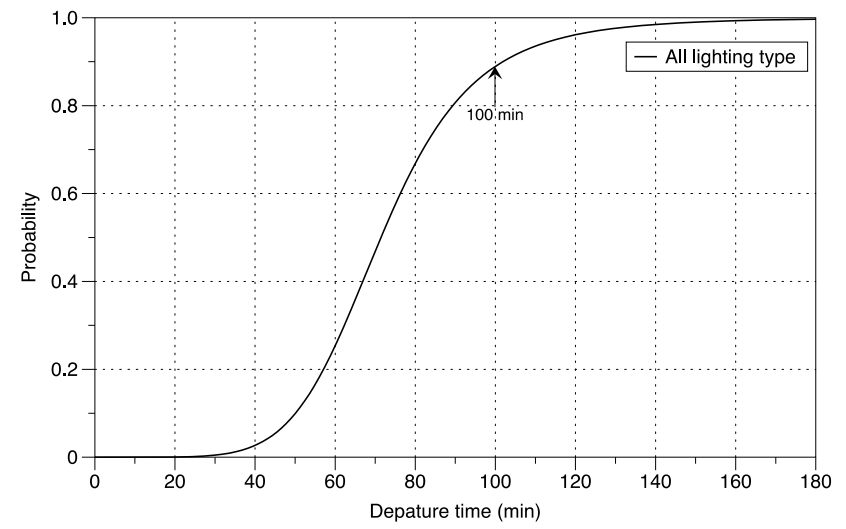

(b) Probability curve of lights off when occupant leave 
Fig.9 Probability curves of different types of occupants turning on and off lighting

From Fig.9 (a) it can be seen that the probability of turning on lights under different illumination levels is different between occupants with different brightness acceptable levels. With increased indoor illumination, the probability of turning on lights of various types of occupants showed a rapid decline. Starting from 170lx (dark environment acceptable type) to 320lx (bright environment acceptable type), the probability of turning on lights gradually decreased with increasing illumination. For bright environment acceptable type, the probability of turning on lights when indoor illumination approaching 500lx was almost zero, and for medium environment acceptable type and dark environment ac ceptable type, the probability of turning on lights approached zero at around 300lx and 400lx, respectively.

From Fig. 9 (b) it can be seen that as occupants leave for longer periods of time, the probability of turning off the lights increases. When departure time was within 40 minutes, the probability increased slowly with time. Within $40-$ 100 minutes, the probability showed a sharp upward trend with time. When the departure time reaches $100 \mathrm{~min}$, the probability of occupants' turning off behavior increases gradually slowly. Until 140 minutes, the probability of turning off lights was close to 1, meaning that when occupants left their offic es longer than 140 minutes, it could be generally believed that they would turn off their office lights.

Table 7 Models and parameters of light-on and light-off probability for different types of occupant

\begin{tabular}{c|cccc}
\hline \multicolumn{1}{c}{ Behavior } & Type & Parameters & Probability model \\
& $\begin{array}{c}\text { Bright environment } \\
\text { acceptable type }\end{array}$ & $\begin{array}{c}\gamma=-9.857 \\
k=-4.238 \quad \lambda=184\end{array}$ & $\mathrm{p}=1-\frac{1}{1+\left(\frac{x+9.857}{184}\right)^{-4.238}}$ \\
$\begin{array}{c}\text { Turn on } \\
\text { the light }\end{array}$ & $\begin{array}{c}\text { Medium environment } \\
\text { ac ceptable type }\end{array}$ & $k=-3.945 \quad \lambda=142.29$ & $\mathrm{p}=1-\frac{1}{1+\left(\frac{x+0.13}{142.29}\right)^{-3.945}}$ \\
& $\begin{array}{c}\gamma=-0.13 \\
\text { Dark environment } \\
\text { acceptable type }\end{array}$ & $k=-5.709 \quad \lambda=120.101$ & $\mathrm{p}=1-\frac{1}{1+\left(\frac{x+3.536}{120.101}\right)^{-5.709}}$ \\
\hline $\begin{array}{c}\text { Turn off } \\
\text { the light }\end{array}$ & All the three type & $k=6.191 \quad \lambda=0.014$ & $\mathrm{p}=1-\frac{1}{1+0.014 t^{6.191}}$ \\
\hline
\end{tabular}

\subsection{Shading behavior analysis and model establishment}

According to the field measured data in this study, shading can be classified according to its initial proportion. The changes of MSO and SMR with different initial shading ratios were calculated and shown in Fig.10. 

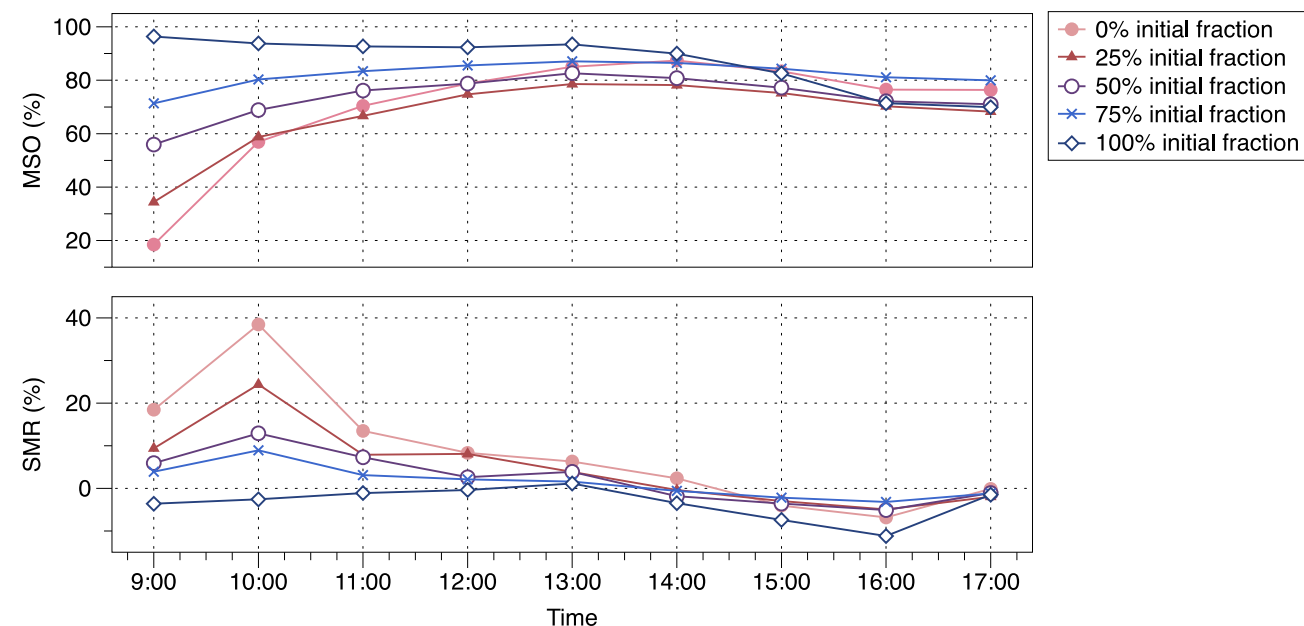

Fig. 10 SMR and MSO for different initial fraction

It can be seen from Fig. 10 that although initial fraction was different, the variation trend of MSO was similar except for initial proportion of 100\%. Before 14:00, shading fraction showed an upward trend, but the increasing rate gradually decreased. The increase was most notic eable between 9:00 and 10:00, and it can be seen that the smaller the initial fraction, the greater the increase. The proportion of shading after 14:00 showed a downward trend as a whole, and the reduction of shading fraction was much smaller than the increase of shading in the morning time. It can be seen that occupants wer more active in blocking glare by pulling shade, and once shade was pulled down, it was rarely pulled up again to obtain daylight. In addition, even if initial shade fraction was significantly different, final MSO tended to be consistent. That is to say, regardless of initial proportion, the shading positions at the end of the day were basically the same, close to about $75 \%$.

Although initial fractions were different, the SMR trend was similar except for $100 \%$ initial fraction. There was a gradual upward trend before 10:00, that is, the amplitude of the shade was gradually increased until the maximum pull-down was reached at 10:00. The smaller the initial fraction was, the larger the pull-down would be. After 10:00, the pull-down of shade gradually decreased, and shade pull-up began to appear gradually at 15:00, and pull-up reached its maximum at 16:00. Because general work plane illumination reached maximum at 10:00 am, occupants often reduced the impact of glare by pulling down shade. The smaller the initial shading fraction was, the more it needed to be pulled down. In the afternoon, especially after 16:00, due to the adjustment of shade in the morning, the shading position would be very low. The indoor illumination at this time would be lower than 500lx and the situation of pulling up shade was more likely to occur.

According to the classification of different types of occupant in the questionnaire, three different types of office shading control were explored. The establishm ent of Markov model refers to the method of Yao [18]. Because indoor workplane illumination has been identified as the driving factor for shading adjustment, indoor workplane illumination is selected as the criterion for constructing Markov transform ation matrix for each type of occupant. In order to better reflect the shading control behavior of occupant under different sky conditions, through the analysis of measured data and previous studies on shading behavior [34-36], the illumination level of 2000lx was finally selected as the dividing line to construct four transition matrices.

Taking the sensitive-type occupant as an example, the actual range can be divided into four situations as follows:

1) "Keep <2000lx", indicates that the indoor workplane illumination at the previous and current moment is less than 20001x;

2) "From $<20001 x$ to $>=20001 x "$ ", indicates that the illumination of indoor workplane at the previous time is $<20001 x$, and that of indoor workplane at the current time is $>=20001 x$; 
3) " Keep $>=20001 x$ ", indicates that the indoor workplane illum ination at the previous moment and the current moment is >2000lx;

4) " From $>=20001 x$ to $<20001 x$ ", means that the illumination of indoor workplane at the previous time $>=20001 x$, while the illumination of indoor workplane at the current time is $<20001 x$.

The above four transition matrices can reflect different behavior characters of adjustment action on shades under different illum ination conditions. In addition, in order to improve the accuracy of the description of shading control behavior, the shading position was divided into 5 parts, respectively $0 \%, 25 \%, 50 \%, 75 \%$ and $100 \%$. Finally, the Markov shading transition model for three different types of occupant within four illum ination conditions can be obtained. The shading transition probabilities of sensitive type occupants in each illuminance conditions is shown in Fig.11. The shading transition probabilities of rem aining types are shown in Fig.A1 of the Appendix.

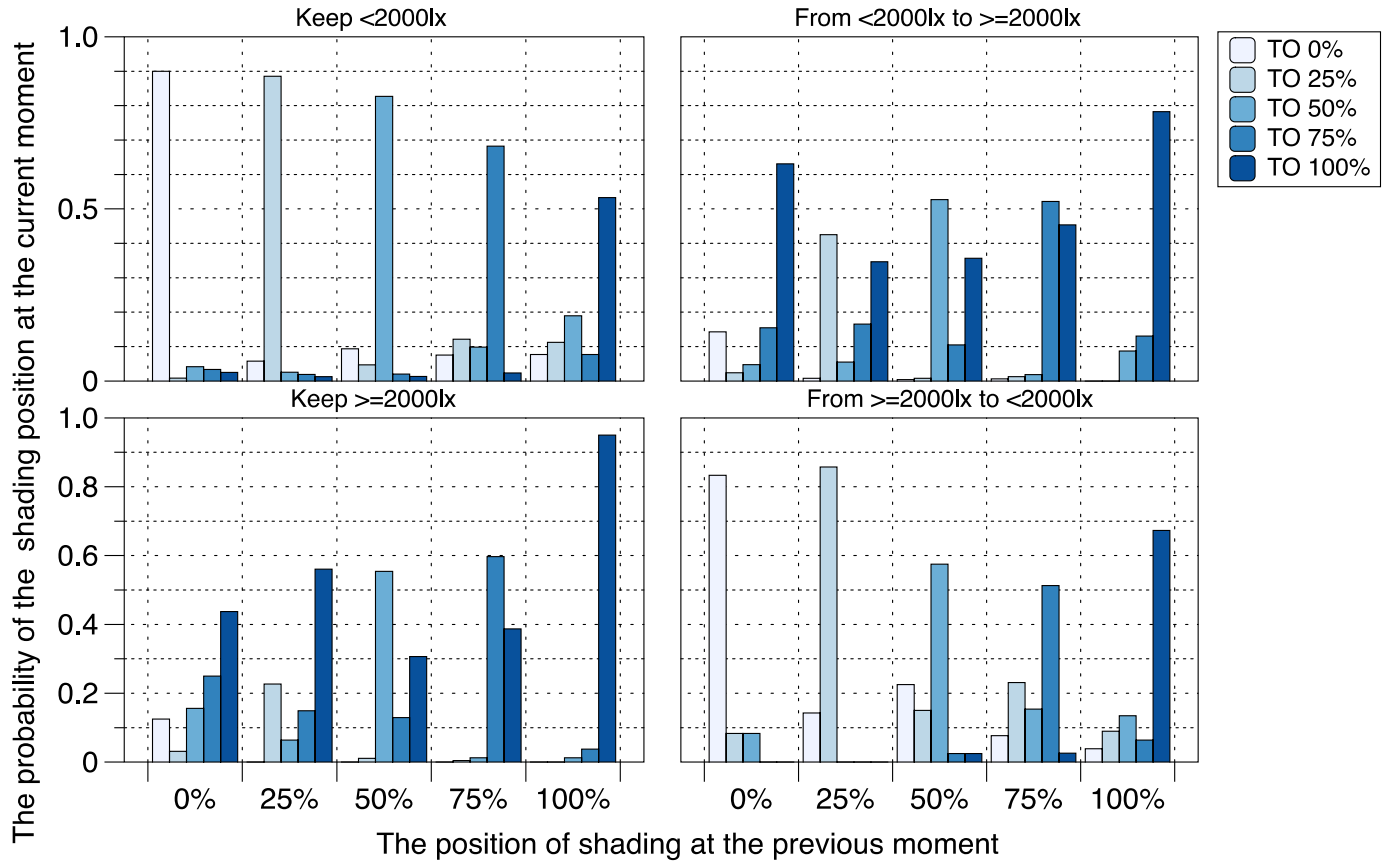

Fig.11 Shading transition probabilities of sensitive type occupants in each illumination area

It can be seen from Fig. 11 and Fig. Al that the shading adjustment probabilities of occupants with different light sensitivity levels were different in various illumination intervals. Regardless of the illumination interval, with the decrease of the sensitivity of the occupants, the proportion of the shading that remains in the original position gradually increases. In the case of "Keep $<20001 \mathrm{x}$ " and "From $>=20001 \mathrm{x}$ to $<20001 \mathrm{x}$ ", for all occupant types, the higher the initial shading ratio, the greater the possibility of adjustment (especially at 100\%). In a large proportion, occupants were more inclined to open parts of shade instead of fully open. In the "From <2000lx to $>=2000 \mathrm{kx}$ " and "Keep $>=2000 \mathrm{~lx}$ " illuminance intervals, the smaller the initial shading fraction was, the greater the likelihood to adjust the shade would be. Occupants tended to close shade completely, rather than partially closing it. In addition, Furthermore, it can be found that the shading remain in their original fraction for a large proportion of the time regardless of the illuminance interval. It may be assumed that adjustment of shading was not frequent, and occupants preferred to keep its current state until they felt discomfortable.

\subsection{Prediction of occupant's coupling control behavior}

After the light environment preference type, lighting control type and shading control type were determined, the coupling controlbehaviors of different patterns are modeled and predicted. Considered that the different initial shading 
fraction may affect the coupling control of occupants, the coupling control behavior of the five pattern at different initial shading fraction were predicted. Due to the behavior of occupant is stochastic, the results of multiple predictions may be slightly different. Therefore, 100 times predictions on the coupling control behaviors of different pattern were conducted under different initial fraction, and then the prediction control behavior with the largest proportion were selected as the typical control behavior which were listed in Table 8.

Table 8 contains the hourly changes of illuminance and occupant control behavior for the five types of occupants with the five initial shading positions. The shading state can be 0 position, 0.25 position, 0.5 position, 0.75 position or 1 position, while the lighting status can be 0 (switch-off) or 1 (switch-on). It is worth noting that the initial shading position refers to the position where the shading has not been adjusted before the arrival of occupant, while the lighting and shading state in each figure of Table 8 represents the state after occupant adjusted and controlled the illum ination in each hour. 
Table 8 Prediction of coupling control behavior of different pattern under different initial shading fraction

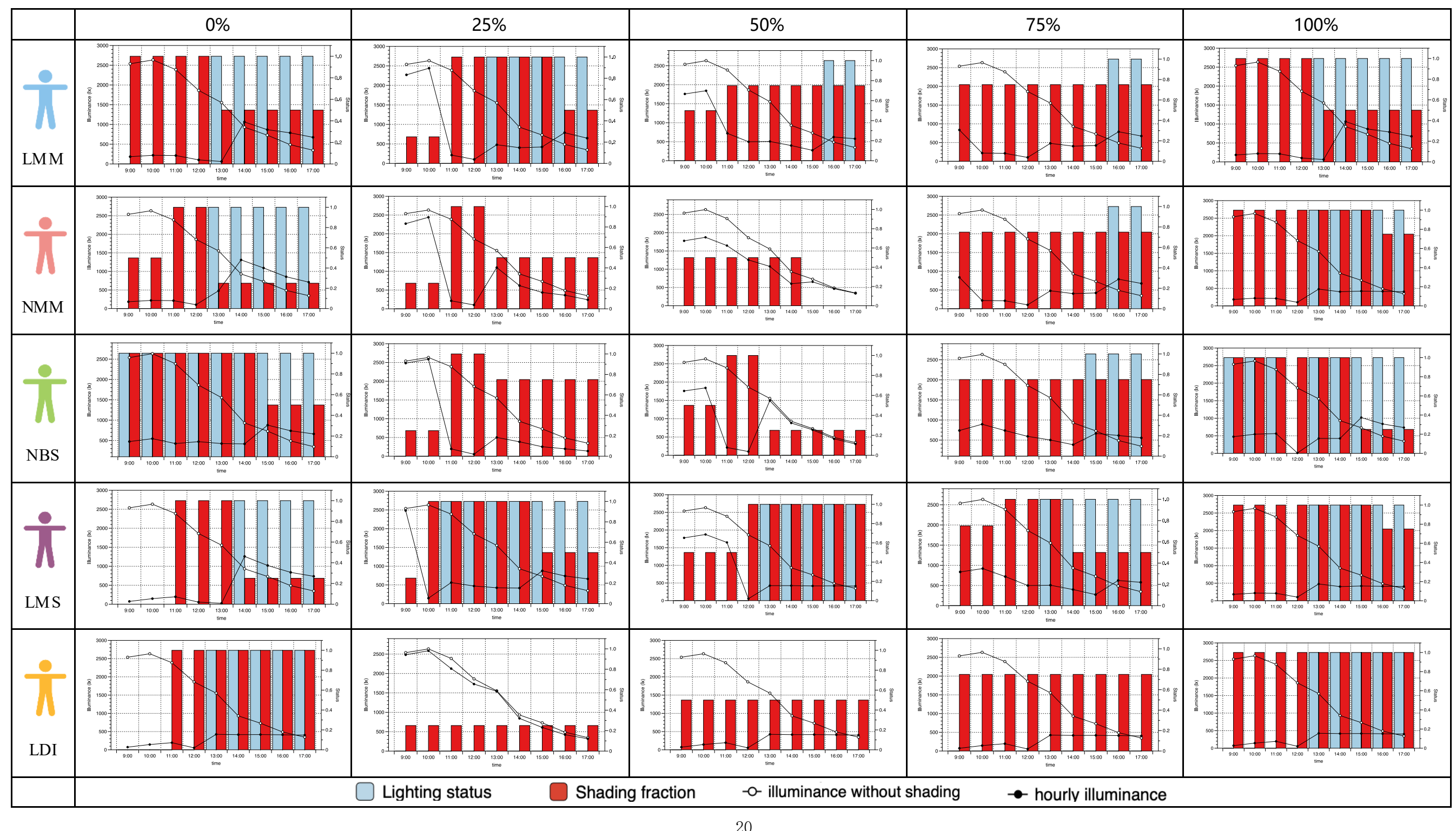


It can be seen from Table 8 that there are some differences between occupant behavior of different pattern and different initial shading fraction in controlling indoor lighting and shading. For the LMM and NMM pattern, in addition to the preference type of the light environment, bright and dark acceptance and light sensitivity has the same degree of it. The LMM prefers to preferentially control the lighting to obtain sufficient illumination when the indoor light is insufficient. However, when the indoor light is insufficient, the NMM prefers to adjust the shading preferentially to obtain sufficient illumination. It can be seen clearly in the figure that the natural light-preferred NMM has much less lighting demand than the light-preferred LMM. Especially in the case of initial fraction of 0.25 and 0.5 , it can even reach the state of not turning on the lights, so it can be found that the lighting and the natural light preferences type of occupant affect the control behavior according to their own willingness. For the two patterns of LMM and LMS, the sensitivity of the light environment and the acceptance of the bright and dark environment are the same. Due to the occupants of LMS pattern are more sensitive to direct sunlight, the adjustment of the shading is more positive. Therefore, they are more likely to turn on the lights after pulling down the shading. It can also be found that as occupant's acceptance of the dark environment increases, they have less demand for lighting at the same shade fraction.

In addition, for the same pattern, as the initial fraction increases, as the initial ratio increases, the lighting demand in one day tends to decrease first and then rise. That is, for two extreme conditions (fully open or fully closed), it is even possible to turn on lights. And it can be seen that the initial shading fraction per day is critical to the control behavior of the room during the day.

In view of the initial shading fraction, the occupants of LDI pattern have the most demand to turn on the lights, while the LMS pattern occupants have the least need to do it. By comparison, it is found that occupant with natural light preference type do not necessarily make indoor lighting use less, because they are also affected by the acceptance of bright and dark environments and the sensitivity of light. For natural light preference occupant, the more sensitive an occupant is to light, the more frequent the adjustment of the shading, which may result in an increase in lighting demand after the shading is pulled down. In addition, the need for lighting is reduced when occupants become more ac cepting of the dark environment. It can be seen that the light environment preference of occupant, the acceptance of bright and dark environment, the sensitivity of light and the initial fraction of shading will affect the specific control behavior of occupant within one day. Therefore, it is particularly important to fully consider the oc cupant preferences when implementing occupant behavior predictions.

\subsection{Comparison of the traditional model with the new model}

In order to demonstrate the importance of the occupants' preferences and the coupling effect of shading and lighting in the prediction model, the established coupling prediction model established in this study was compared with three other models with different focuses. The specific description of the four models is shown in Table 9. For Model 1, the classification of occupants is considered in the modeling process, as well as the coupling relationship and diversity between occupants, as shown in Fig. 6. For Model 2, the average statistical data was used for modeling. The diversity between occupants in lighting and shading control was not considered, but the coupling relationship between the two systems was considered. For Model 3, it did not consider the coupling relationship between the two systems, and the shading was assumed according to the priority control. For Model 4, the coupling relationship and diversity between occupant were both ignored.

The four models listed in Table 9 were used to predict the actions during the testing period for each control behavior pattern. The schedule formed by the predicted action frequency and duration were then put into EnergyPlus and the lighting energy consumption of the room was simulated for one month. In order to exclude the effect of the initial shading ratio on the predicted results, the period of July 30th to August 29th was select for comparison (the initial shading ratio on the first day of this period is $0 \%$, and the initial shading ratio on each day thereafter is the same 
as that at the end of the previous day).

Considering the difference in the number of occupant of each control behavior pattern, the average values were applied. The final simulation results obtained were the lighting energy consumption of a single room for one month, the predicted results of occupant actions and the lighting energy consumption are shown in Fig. 12 and Fig.13 respectively.

Table 9 Description of four models with different focuses on the occupant preference and the coupling effect of shading and lighting

\begin{tabular}{|c|c|c|c|c|c|c|}
\hline Model & Diversity & Lig & ng model & & rodel & Coupling \\
\hline \multirow{3}{*}{ Model 1} & \multirow{3}{*}{$r$} & B-type & $\begin{array}{c}\gamma_{1}=-9.857 \\
\lambda_{1}=184 \\
k_{1}=-4.238\end{array}$ & S-type & $\boldsymbol{P}_{B_{i j}}$ & \multirow{3}{*}{$r$} \\
\hline & & M-type & $\begin{array}{l}\gamma_{2}=-0.13 \\
\lambda_{2}=142.29 \\
k_{2}=-3.945\end{array}$ & M-type & $P_{M_{i j}}$ & \\
\hline & & D-type & $\begin{aligned} \gamma_{3} & =-3.536 \\
\lambda_{3} & =120.101 \\
k_{3} & =-5.709\end{aligned}$ & I-type & $\boldsymbol{P}_{\boldsymbol{D}_{i j}}$ & \\
\hline \multirow{3}{*}{ Model 2} & & B-type & \multirow{3}{*}{$\begin{array}{c}\gamma_{0}=-3.52 \\
\lambda_{0}=177.26 \\
k_{0}=-2.58\end{array}$} & S-type & $P_{B_{i j}}$ & \multirow{3}{*}{$\checkmark$} \\
\hline & & M-type & & M-type & $\boldsymbol{P}_{M_{i j}}$ & \\
\hline & & D-type & & I-type & $P_{D_{i j}}$ & \\
\hline \multirow{3}{*}{ Model 3} & \multirow{3}{*}{$\checkmark$} & B-type & $\begin{array}{c}\gamma_{1}=-9.857 \\
\lambda_{1}=184 \\
k_{1}=-4.238\end{array}$ & S-type & \multirow{3}{*}{$P_{i j}$} & \\
\hline & & M-type & $\begin{array}{c}\gamma_{2}=-0.13 \\
\lambda_{2}=142.29 \\
k_{2}=-3.945\end{array}$ & M-type & & \\
\hline & & D-type & $\begin{aligned} \gamma_{3} & =-3.536 \\
\lambda_{3} & =120.101 \\
k_{3} & =-5.709\end{aligned}$ & I-type & & \\
\hline \multirow{3}{*}{ Model4 } & & B-type & $\gamma_{0}=-3.52$ & S-type & \multirow{3}{*}{$P_{i j}$} & \\
\hline & & M-type & $\lambda_{0}=177.26$ & M-type & & \\
\hline & & D-type & $k_{0}=-2.58$ & I-type & & \\
\hline
\end{tabular}

${ }^{*} P_{B_{i j}} P_{M_{i j}} P_{D_{i j}}$ represent the differences in the probability of shading transfer of B-type, M-type and D-type, $P_{i j}$ represents the average probability of shading transfer of all occupant. 


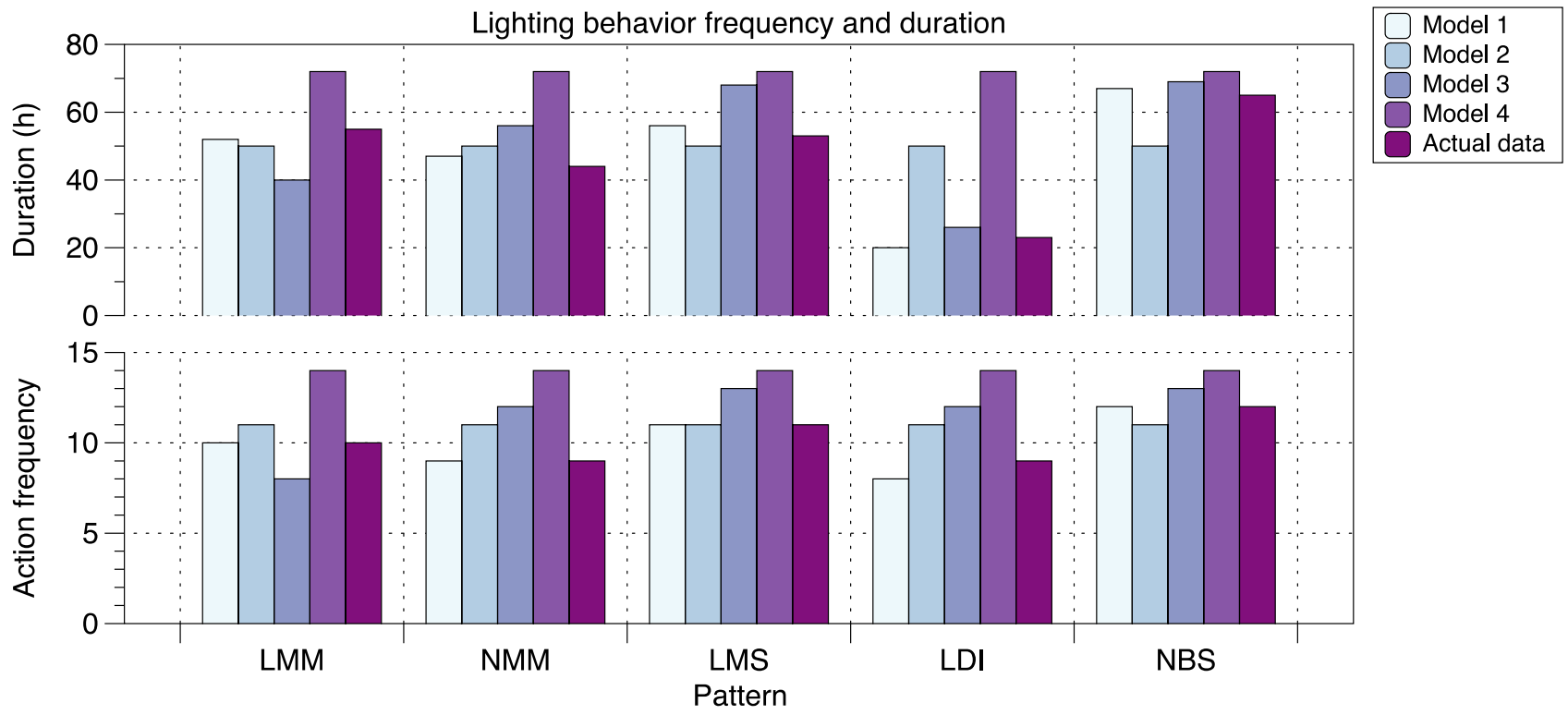

(a) Action frequency and of duration of lighting

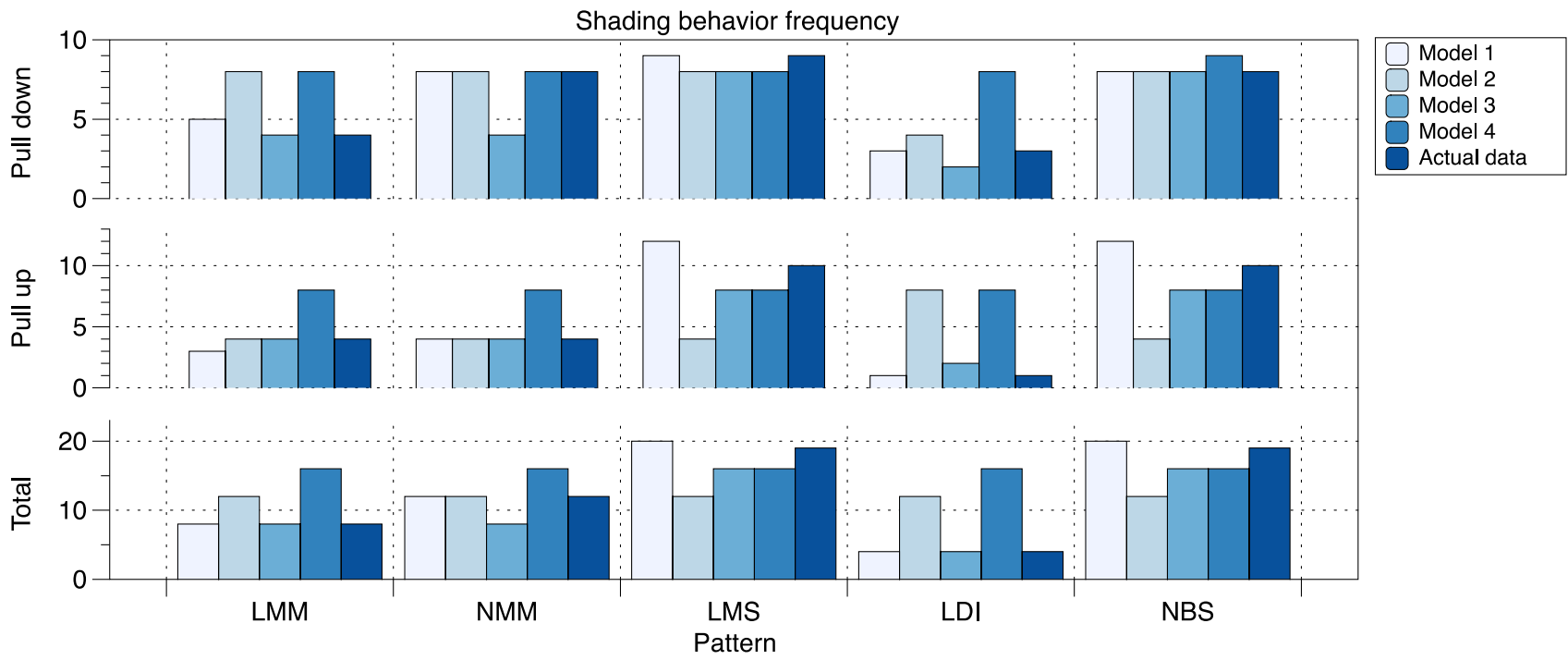

(b) Action frequency and of duration of shading

Fig. 12 Prediction results and validation of occupants actions by four models

According to the actual action record in Fig.12 (a), the lighting operation frequency is arranged from large to small as NBS,LMS,NMM/LMM and LDI, and the lighting duration is also NBS,LMS, LMM,NMM and LDI in order from large to small. Therefore, it can be seen that there are certain differences in the lighting and shading opening frequency of different pattern of oc cupant. For occupant like NBS pattern, the frequency and duration of lighting are at the highest. In addition, it can be seen from Fig.12 (b) that NBS has the highest shading adjustment times and the highest pull-up frequency. For LDI, the adjustment frequency is very low regardless of lighting and shading, and once adjusted, it will stay in this state for a long time.

In general, Model 4 has the worst prediction accuracy because it fails to consider the diversity of people and the coupling effect. The worst prediction of lighting behavior frequency occurs in the prediction of LDI pattern, with an error of $35.71 \%$. In addition, it can be seen that the prediction accuracy of Model 2 is better than that of Model 3. Therefore, in the prediction of action frequency, it is more important to consider the coupling effect than the diversity 
betw een occupants. By contrast, Model 1 shows a good performance in predicting the number of actions of occupants, and its prediction accuracy of lighting and shading behavior frequency can reach $100 \%$ in some cases, while the worst case is only 1 time deviation from the record data.

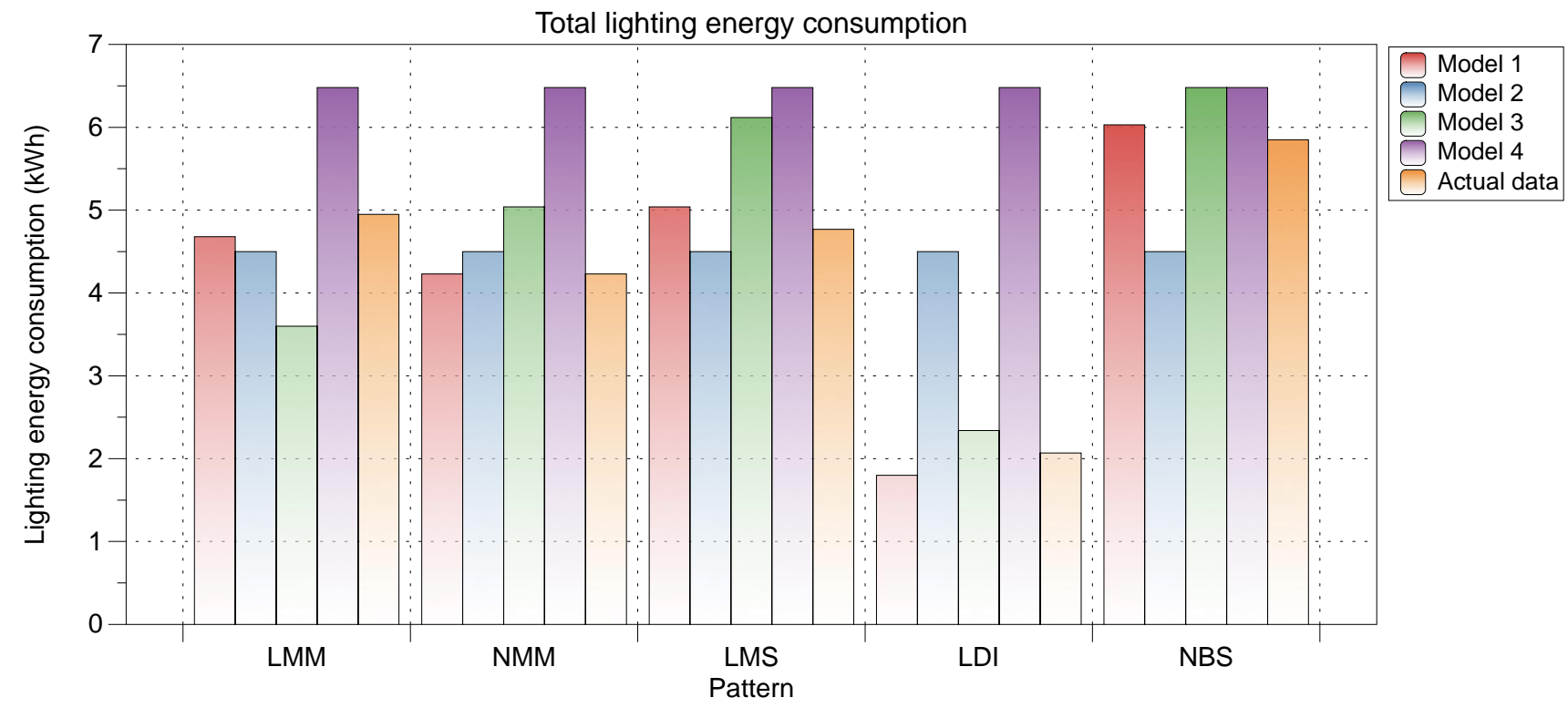

Fig.13 Prediction results and validation of lighting energy consumption by four models

It can be seen from Fig. 13 that the energy consumption prediction error ranges of the four models are 3.07\% to 13.04\% (Model 1), $9.09 \%$ to $117.39 \%$ (Model 2), 6.15\% to 27.27\% (Model 3) and 30.9\% to 63.63\% (Model 4) respectively. Therefore, for the prediction performance of lighting duration and lighting energy consumption, Model 1>, Model 3>, Model 2>, Model 4. This is due to the fact that for occupant who are not sensitive to light and have a preference for dark environment, the adjustment frequency is low, but the shading state will remains for a long time after adjustment. In addition, the occupant preference seems more important in the behavior prediction for the occupant with LDI pattern. Although Model 2 has better performance that Model 3 in most cases, when the occupant belongs to LDI pattern, the prediction error of Model 2 becomes larger than that of Model 3.

To evaluate the prediction performance of the four models, root mean square error (RMSE) and mean absolute error (MAE) are applied.

$$
\begin{gathered}
R M S E=\sqrt{\frac{1}{N} \sum_{i=1}^{N}\left(y_{i}-\widehat{y}_{\imath}\right)^{2}} \\
M A E=\frac{1}{N} \sum_{i=1}^{N}\left|y_{i}-\widehat{y}_{\imath}\right|
\end{gathered}
$$

Where $y_{i}$ and $\widehat{y}_{i}$ are the actual and predicted lighting energy consumption at time $i$, respectively, and $N$ is the total length of the data. The first error, the RSME, amplifies the larger error using the squared form, while the second error, the MAE, describes how close the prediction and measurement are to the absolute scale. The prediction errors are shown in Table 10.

Table 10 Accuracy of the prediction results

\begin{tabular}{ccc}
\hline & RMSE & MAE \\
\hline Model 1 & 0.073 & 0.052 \\
\hline Model 2 & 0.184 & 0.158 \\
\hline Model 3 & 0.132 & 0.121 \\
\hline Model 4 & 0.273 & 0.226 \\
\hline
\end{tabular}

According to Table 10, the performance of Model 1 is better than other models. In general, the proposed model 
comprehensively considered the diversity of occupant and the coupling relationship between shading and lighting.

Although this study only selected indoor light environment of south-facing office rooms in summer for model validation, the modeling approach, which takes the interaction of behavior and diversity of people into account, may be extended to office rooms with other orientations and office buildings under other climatic conditions. The following aspects are expected to be improved in future studies on shading and lighting control behavior predictions. 1) The prediction model is only usable for private offices. Because both control desire and control device ownership will be different for occupants in multi-occupant offcies, their behavior will be quite different to the behavior in private office rooms. 2) Surveys along with field measurements were only conducted to 12 occupants in the selected private offices. The sample size needs to be increased in future research to strengthen the findings from this study.

\section{Conclusions}

Lighting and shading behavior of occupant is an important factor affecting indoor lighting and lighting energy consumption. There are differences in the regulation of lighting and shading by different people, and there is a certain correlation between lighting and shading behavior. However, the research on lighting and shading behavior cannot fully consider the diversity of people, and often ignores the linkage between lighting and shading behavior. In order to fully consider the diversity of people and the interaction between lighting and shading behavior, this study has taken an office building in Wuhan, China, as a case study to verify coupling control behavior prediction model of shading and lighting. Questionnaires were used to classify light environment preferences and usage habits on both shading and lighting in the offic e building. Based on statistical results from questionnaires and working surface illuminance forecast by the GBR machine learning model, the proposed model has been justified as usable for judging indoor occupant lighting and shading coupling control behavior. Main conclusions from this study included:

1) For occupants' lighting control behavior, difference between occupants existed in terms of their probabilities of turning on lights under different illumination levels. With increasing indoor illumination, the probability of turning on lights of various types of occupants showed a rapid decline. Starting from 170lx (insensitive type) to 320lx (sensitive type), the probability of turning on lights gradually decreased with increasing illumination. For sensitive people, the probability of turning on lights when indoor illumination approached 500lx was close to zero. For moderate and insensitive types, the probabilities of turning on lights approached zero at around 300lx and 4001x, respectively.

2) For occupants' shading control behavior, difference between occupants existed in shading adjustment probabilities under different illumination levels. Regardless of illumination levels, the shading ratio was always likely to remain at previous states. As the sensitivity of the occupants decreases, the probability of the shading remaining in its former state increases. When closing shade, occupants tended to fully close it instead of closing part of it. On the contrary, when opening shade, occupants tended to open part of it instead of fully open it.

3) When describing lighting-shading coupling control behavior, diversity between occupants and coupling between behaviors have shown great influence on the prediction accuracy. The prediction results of four models were compared, and it was found that the proposed coupling prediction models showed the best performance. For predicting lighting energy consumption, the maximum error rate was only $13.04 \%$. In addition, it was found that the coupling effect had bigger impact on accuracy improvement of behavior prediction models, but the impact from occupants' preference dominated if the occupant was insensitive to light and was able to endure a dark working environment. 


\section{Acknowledgement}

This work is supported by the Nature Science Foundation of Tianjin (19JCQNJC07000) and has been benefited from broader discussion of occupant behavior in the International Energy Agency Energy in Buildings and Communities Program (IEA EBC) Annex 79: Occupant behavior-centric building design and operation.

\section{Appendix}

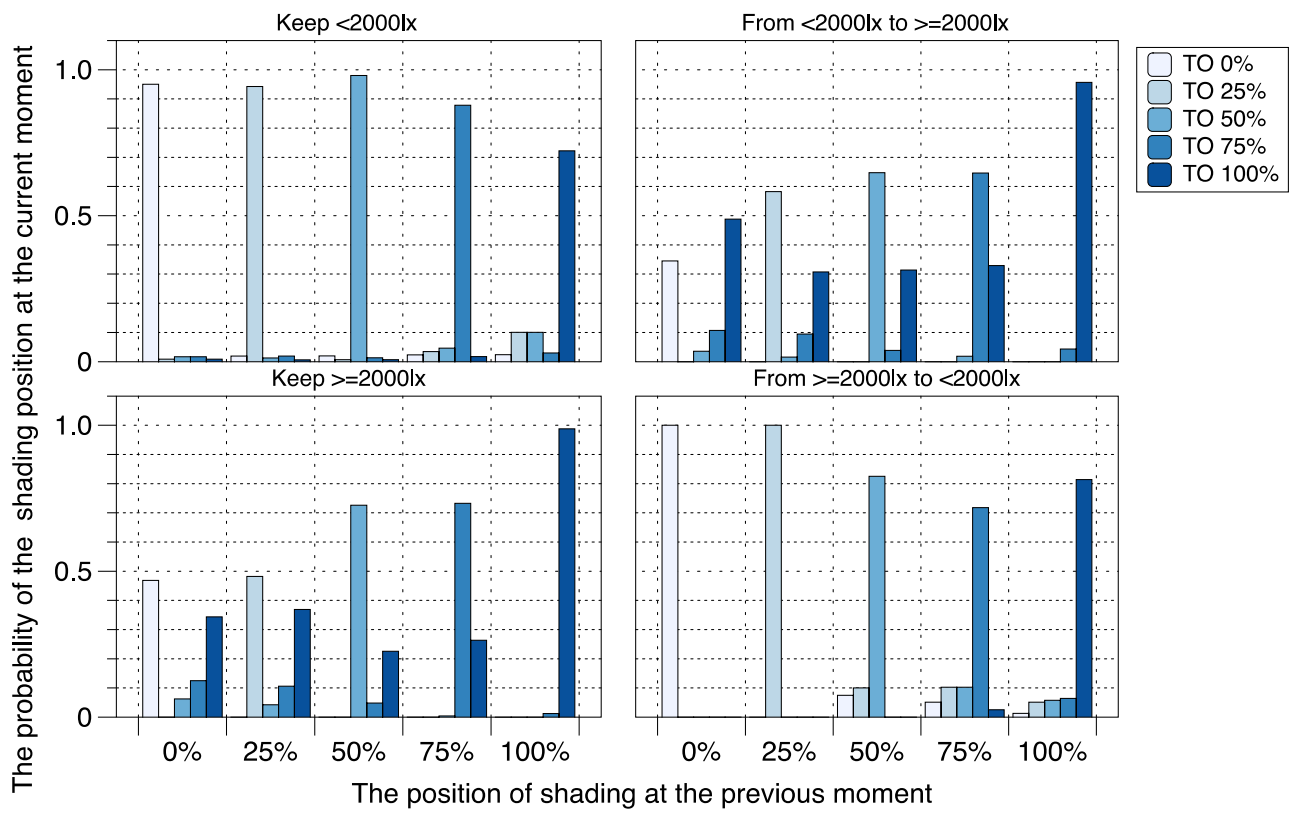

(a) Medium type occupant

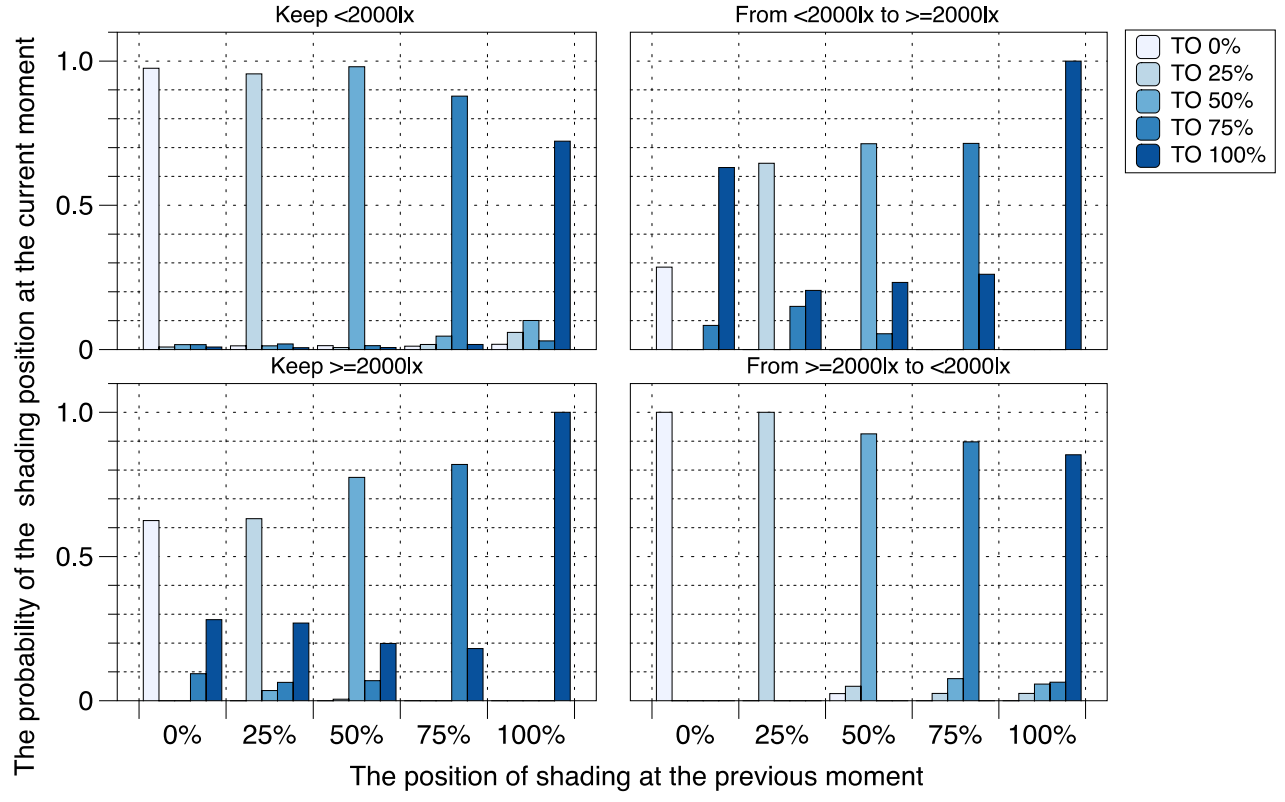

(a) Insensitive ty pe occupant

Fig. A1 Shading transfer status of different types of occupant 


\section{Reference}

[1] Aldossary NA, Rezgui Y, Kwan A. Domestic energy consumption patterns in a hot and humid climate: a multiplecase study analysis. Appl Energy 2014;114:353-65.

[2] Building Energy Research Center in Tsinghua University. 2018 Annual Report on China Building Energy Efficiency. China Building Industrial Publishing, Beijing, 2018 [in Chinese].

[3] C. Wang, D. Yan, X.X. Ren, Modeling individual's light switching behavior to understand lighting energy use of office building, Enrgy Proced 88 (2016) 781-787.

[4] J. Xiong, A. Tzempelikos, I. Bilionis, P. Karava, A personalized daylighting control approach to dynamically optimize visual satisfaction and lighting energy use, Energ Buildings 193 (2019) 111-126.

[5] Da Yan, William O'Brien, Tianzhen Hong, Xiaohang Feng, H. Burak Gunay, Farhang Tahmasebi, Ardeshir Mahdavi, Occupant behavior modeling for building performance simulation: Current state and future challenges, Energy and Buildings 107 (2015) 264-278.

[6] V.E. IES, Integrated environmental solutions virtual environment, 2015.

[7] Ahmad Sabry An-Naggar, Mohamed Aly Ibrahim, Essam E. Khalil, Energy Performance Simulation in Residential Buildings, Procedia Engineering 205 (2017) 4187-4194.

[8] U.S. Department of Energy, Input Output Reference, EnergyPlus Version 9.0.1 Documentation.

[9] V. Inkarojrit, Monitoring and modelling of manually-controlled venetianblinds in private offices: a pilot study, J. Build. Perform. Simul. 1 (2008) 75-89.

[10] Y.W. Jian, Y. Li, S. Wei, Y.F. Zhang, Z. Bai, A Case Study on Household Electricity Uses and Their Variations Due to Occupant Behavior in Chinese Apartments in Beijing, J Asian Archit Build 14(3) (2015) 679-686.

[11] Gilani S , O'Brien W , Gunay H B , et al. Use of dynamic occupant behavior models in the building design and code compliance processes[J]. Energy \& Buildings, 2016, 117:260- y \& Buildings, 2016, 117:260-27

[12] Da Yan, Xiaohang Feng, Yuan Jin, Chuang Wang. The evaluation of stochastic occupant behavior models from an application-oriented perspective: Using the lighting behavior model as a case study, Energy and Buildings, 176 (2018) 151-162.

[13] Mahdavi, Tahmasebi, 2015. Predicting people's presence in buildings: An empirically based model performance analysis. Energy and Buildings, 86, 349-355.

[14] Hunt ,1980. Predicting artificial lighting use-a method based upon observed patterns of behavior. Lighting Research \& Technology, 12, 7-14.

[15] D. Robinson, F. Haldi, An integrated adaptive model for overheating risk prediction, Building Simulation 2007, Vols 1-3, Proceedings (2007) 745-750.

[16] Wang, C., Yan, D., Sun, H. \& Jiang, Y. 2016. A generalized probabilistic formula relating occupant behavior to environmental conditions. Building and Environment, 95, 53-62.

[17] Van Den Wymelenberg, K. Patterns of occupant interaction with window blinds: A literature review. Energy and Buildings, 2012, 51: 165-176.

[18] Amir Nezam doost, Kevin Van Den Wymelenberg, A daylighting field study using human feedback and simulations to test and improve recently adopted annual daylight performance metrics. Journal of Building Performance Sim ulation, 2017, 10:5-6, 471-483.

[19] Jian Yao, Determining the energy performance of manually controlled solar shades: A stochastic model based cosimulation analysis, Applied Energy 127 (2014) 64-80

[20] Jian Yao, David Hou Chi Chow, Rong-Yue Zheng \& Cheng-Wen Yan, Occupants' impact on indoor thermal comfort:a co-simulation study on stochastic control of solar shades, Journal of Building Performance Simulation(2016) 
[21] Frédéric Haldi, DarrenRobinson. Adaptive actions on shading devices in response to local visual stimuli[J]. Journal of Building Performance Simulation, 2010, 3(2):135-153.

[22] Seyed Amir Sadeghi, Nimish M. Awalgaonkar, Panagiota Karava, Ilias Bilionis, A Bayesian modeling approach of human interactions with shading and electric lighting systems in private offices, Energy and Buildings 134 (2017) $185-201$

[23] Christoph F. Reinhart, Lightswitch-2002: a model for manualand automated control of electric lighting and blinds, Solar Energy 77 (2004) 15-28.

[24] S. Wei, R. Buswell, D. Loveday, Probabilistic modelling of human adaptive behavior in non-air-conditioned buildings Adapt. to Chang. New Think. Comf., 55, 2010, pp. 9-11

[25] H.B. Gunay, W. O'Brien, I. Beausoleil-Morrison, B. Huchuk, On adaptive occupant-learning window blind and lighting controls, Build Res Inf 42(6) (2014) 739-756.

[26] H.B. Gunay, W. O'Brien, I. Beausoleil-Morrison, R. Goldstein, S. Breslav, A. Khan, Coupling stochastic occupant models to building performance simulation using the discrete event system specification formalism, J Build Perform Simu 7(6) (2014) 457-478.

[27] S. D'Oca, T. Hong, A data-mining approach to discover patterns of window opening and closing behavior in offices, Build. Environ. 82 (2014) 726-739.

[28] Z. Yu, B.C. Fung, F. Haghighat, H. Yoshino, E. Morofsky, A systematic procedure to study the influence of occupant behavior on building energy consumption, Energy Build. 43 (6) (2011) 1409-1417.

[29] Xiaohang Feng, Da Yan *, Chuang Wang, Hongsan Sun, A preliminary research on the derivation of typical occupant behavior based on large-scale questionnaire surveys, Energy and Buildings 117 (2016) 332-340.

[30] Friedman, J.H. Greedy function approximation: a gradient boosting machine. Ann.Stat. 29, 1189-1232.

[31] Inoue T, Kaw ase T, Ibamoto T, Takakusa S, Matsuo Y. The development of an optimal control system for window shading devices based on investigations in office buildings. ASHRAE Trans 1988;94:1034e49.

[32] D. Lindelo€f, N. Morel, A field investigation of the intermediate light switching by users, Energy Build. 38 (2006) 790e801, http://dx.doi.org/10.1016/ j.enbuild.2006.03.003.

[33] C.F. Reinhart, K. Voss, Monitoring manual control of electric lighting and blinds, Light. Res. Technol. 35 (2003) 243e258, http://dx.doi.org/10.1191/ 1365782803li064oa.

[34] Jie Xiong, Athanasios Tzempelikos ,Model-based shading and lighting controls considering visual comfort and energy use ,Solar Energy: 134 (2016) 416-428

[35] Nabil, A., Mardaljevic, J., 2006. Useful daylight illuminances: a replace- ment for daylight factors. Energy Build. 38 (7), 905-913.

[36] Shen, H., Tzempelikos, A., 2014. Aglobal method for efficient synchro- nized shading control using the "effective daylight" concept. In: Proceedings of 3rd International High Performance Buildings Con- ference at Purdue, West Lafayette, Indiana, 8 pages. 